\title{
The axial postcranial structure of Griphognathus whitei from the Upper Devonian Gogo Formation of Western Australia: comparisons with other Devonian Dipnoans
}

\author{
K.S.W. Campbell and R.E. Barwick \\ Geology Department, Australian National University, Canberra, 0200, Australia. \\ e-mail ken.campbell@ anu.edu.au and richard.barwick@ anu.edu.au
}

\begin{abstract}
The skeleton of the pectoral and pelvic girdles, the foremost axial region, and the scales of Griphognathus whitei, and the pectoral and pelvic girdles and scales of Chirodipterus australis, have been described previously. The posterior parts of the postcranial skeleton of these fishes have been commented on in passing, but new material permits a description of the centra, the neural and haemal arches and the incomplete medial fins of $G$. whitei. The limb skeletons have not been preserved in our material. The new material of G. whitei adds considerably to the information available on the axial skeleton and the medial fins of Devonian dipnoans. Of these dipnoans, only Dipterus has the axial skeleton without the centra well preserved, though fragments of the centra of some of the other genera are poorly preserved. The new specimens of $G$. whitei have well preserved centra along the full length of the body of the animal. The neural and haemal arches give the best information available on Devonian species. The medial fins are sufficiently well preserved to compare with those of Fleurantia and Scaumenacia from the Upper Devonian of Canada, and the Australian Barwickia and Howidipterus from the Givetian of Victoria. Gross differences occur between all the above genera in the structure of the medial fins. The function of the fins and the centra are discussed, and an attempt is made to show how the whole structure of the movement of $G$. whitei is related to the bottom dwelling environment in which the animals lived.
\end{abstract}

\section{INTRODUCTION}

From the Gogo Formation in the Canning Basin of Western Australia, the lungfishes Griphognathus whitei and Chirodipterus australis have parts of the postcranial skeleton preserved, and fragments of Holodipterus are available but we do not have sufficient material at present to be worth describing. Of these Griphognathus is the best preserved, and work on the anterior vertebral column has already been published (Campbell and Barwick 1988, 1999). Pridmore and Barwick (1993) also figured parts of the vertebral column and the median fins, but did not comment on the details. The structure of the pectoral girdle and the pelvic girdle have been described (Young et al. 1989; Campbell and Barwick 1999). No examples of the pectoral or pelvic fins have been observed.

We now have a more or less complete body of Griphognathus whitei which lacks its caudal fin. Nineteen other specimens have been prepared, some of which show details of the posterior end of the skeleton, others show the detail of a number of axial segments, others show the centra and the ribs, and still others show the support structures of the medial fins and their lepidotrichs. Scale coverings of the fins are also partly known. In addition we have specimens of Griphognathus in which several ribs are preserved. The attachment of the ribs to the centra are well preserved and the shapes of the ribs and their attachment surfaces are clear. These features are not known from any other Devonian dipnoans.

In none of the previous works is there any discussion of the articulations of the elements, presumably because they were not preserved. The Gogo material permits an examination of the articulations and hence a better understanding of the function of the fins and the body during locomotion.

\section{TERMINOLOGY}

We will not discuss the details of relationships between sarcopterygians, and so there will be no need to become involved with a discussion of terminology as it might apply to other groups as well as dipnoans. So that our work will fit in with what is being done in other Palaeozoic dipnoans, we will use the terminology used by Ahlberg and Trewin (1995) in describing the axial skeleton of 
Dipterus valenciennesi. In so doing we will provide a basis for the direct comparison with the most recently described species which occurs in rocks older than our material. More recently, Cloutier (1996) has described the postcranial exoskeleton of the Late Devonian Scaumenacia and Fleurantia from Canada, and these species show structures not known in Dipterus valenciennesi. Where appropriate we have used Cloutier's terminology.

\section{PREVIOUS WORK ON THE POSTCRANIAL STRUCTURE OF DEVONIAN DIPNOANS}

Ahlberg and Trewin (1995) in a discussion of the postcranial skeleton of Dipterus valenciennesi, mentioned the lack of information on the postcranial skeleton of Devonian dipnoans. The reason for this is clear; so few specimens have been found showing the structures in position, and only a few genera have ossified centra. Specimens found in shale provide most of the data available. Their vertebrae were cartilagenous or were crushed, and the fin supports are hidden beneath the strong covering of scales. Isolated vertebral centra have been used to describe their internal structure (Schultze 1970), but there are too few of these to make a consistent statement about Devonian dipnoans. The discovery of postcranial skeletons from Gogo, sometimes in association with much of the body, offers the opportunity to develop this information in this "potentially important field" (Ahlberg and Trewin 1995: 159).

Schultze (1970) described the axial centra of Griphognathus sculpta and G. multidens from Germany, and Jarvikia and ?Soederberghia from Greenland. The main purpose of his paper was to examine the vertebral structures, attempting to understand the similarities and differences between dipnoans and other sarcopterygians. He came to the conclusion that their structures "show that it is more convincing to place the dipnoans with the teleostomes and near the crossopterygians, rather than place them with the elasmobranchiomorphs....". On the other hand he concluded that the evidence indicated a "much stronger comparison with the vertebrae of other teleostomes or tetrapods". The axial skeleton of Rhinodipterus ulrichi, Dipterus of valenciennesi, and Griphognathus sculpta, have been described from various localities in Europe by Schultze (1975), but they added little evidence because of the poverty of the material available.

The most complete work on the European Devonian genera is that of Ahlberg and Trewin (1995). This dealt with Dipterus valenciennesi. It discussed the evidence from a number of specimens from Scotland, and described parts of the axial skeleton, the haemal and neural arches, and the medial fins. Much of the material was poorly preserved, and few of the fine details were available for description. For example, no information on the internal structure of the centra, and no structures of the haemal or neural arches were available, the organisation of the ribs was not displayed, and the support structures for the median fins were only partly exposed.

More recently, Cloutier (1996) has provided a list of the work previously done on the Canadian genera Scaumenacia and Fleurantia. Jarvik (1959, 1980) has also commented on these genera, following up the work done by Graham-Smith and Westoll (1937). Cloutier's work is more complete, and for the first time the postcranial skeleton of Scaumenacia has been described in detail. This work provides the best account of the Canadian genera.

Long (1993) described the postcranial ribs in a number of Devonian dipnoan genera, especially Barwickia and Howidipterus from the Givetian deposits at Mt Howitt in Victoria. He also has further details of these genera in a manuscript, which we have been given permission to examine. These specimens are preserved in shale, and were studied by latex moulds. They are very useful in that they give a better understanding of Australian material than we had previously. They will be dealt with in a later part of this paper.

\section{MATERIALS AND METHODS}

All the specimens examined have been in the collections of the Australian National University Geology Department (ANU), the Western Australian Museum (WAM), and the Australian Museum, Sydney (AMF). Apart from one specimen collected from South of Lloyd's Hill, all others were collected from Paddy's Valley, Gogo Station, Canning Basin, Western Australia.

ANU 35641; 35645; 49114-49116; 49120; 491207; $49282-49284 ; 49900$.

WAM 87.8.24; 86.9.25; 86.9. 645; 86.9.650; 86.9.651. AMF 72402

All specimens have been prepared by solution of the matrix in acetic acid, impregnating the exposed bone with a dilute plastic, and continuing with the solution until the bone we wished to examine has been exposed.

\section{GROSS STRUCTURE OF GRIPHOGNATHUS WHITEI}

\section{The Structure of the Centra}

As has been illustrated on several occasions (Miles 1977, figures 11, 12, 30; Campbell and Barwick 1999, figures 2,3), the posterior of the skull has centra fused to it and these occupy all the space dorsal to the posterior part of the parasphenoid. 


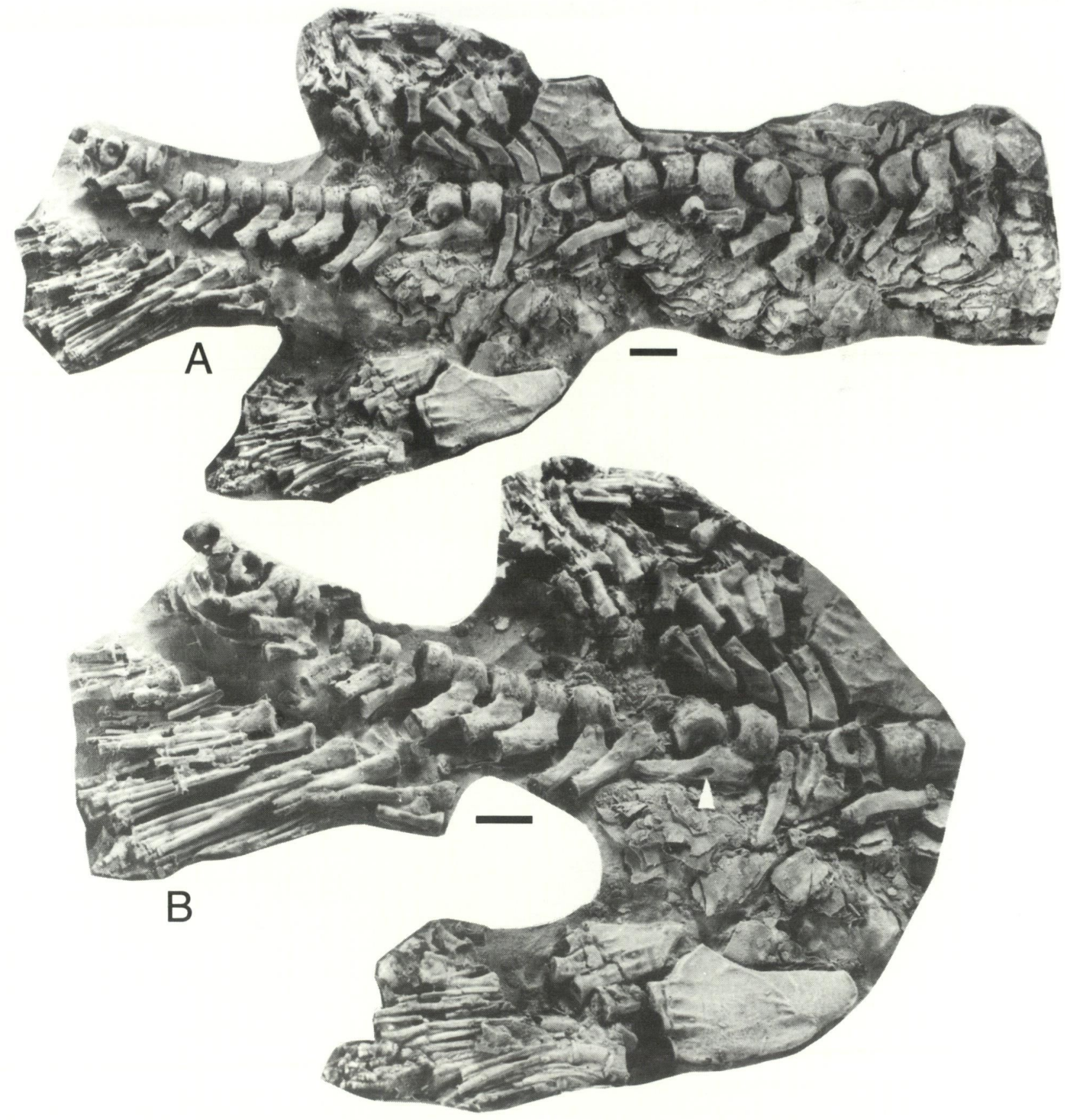

Figure 1 Two views of ANU 49116. A shows the full specimen in lateral view, and B is slightly tilted to show the shapes of the caudal haemal arches. The arrow indicates an opening in the haemal arch for the exit of the caudal artery. Scales $=10 \mathrm{~mm}$.

None of these elements have cranial ribs attached.

The free centra from Griphognathus whitei are well preserved. They include large anterior centra, the fulcral centra, and posterior centra from the caudal region of adults, and some juveniles with centra from a variety of positions along the axial column. It has been possible to section some of them, providing the largest sample of Devonian dipnoan centra yet available. They are apparently single structures, and are not made of units subsequently fused. In this they are quite unlike the centra of other sarcopterygians.
Many segments of ANU 49116 (Figure 1A,B) are known, and in particular those of the proximal part of the caudal region are well preserved. These illustrate the reduction of the length of the centra at a clear cut point along the length of the vertebral column. Three centra at the anterior end of the caudal region average $6.3 \mathrm{~mm}$ long, whereas the next three average $4.5 \mathrm{~mm}$ long. The break in size occurs rapidly. Four more posterior centra are each only $3 \mathrm{~mm}$ long.

We have isolated centra from almost throughout the whole column. In adults they are solid blocks of 


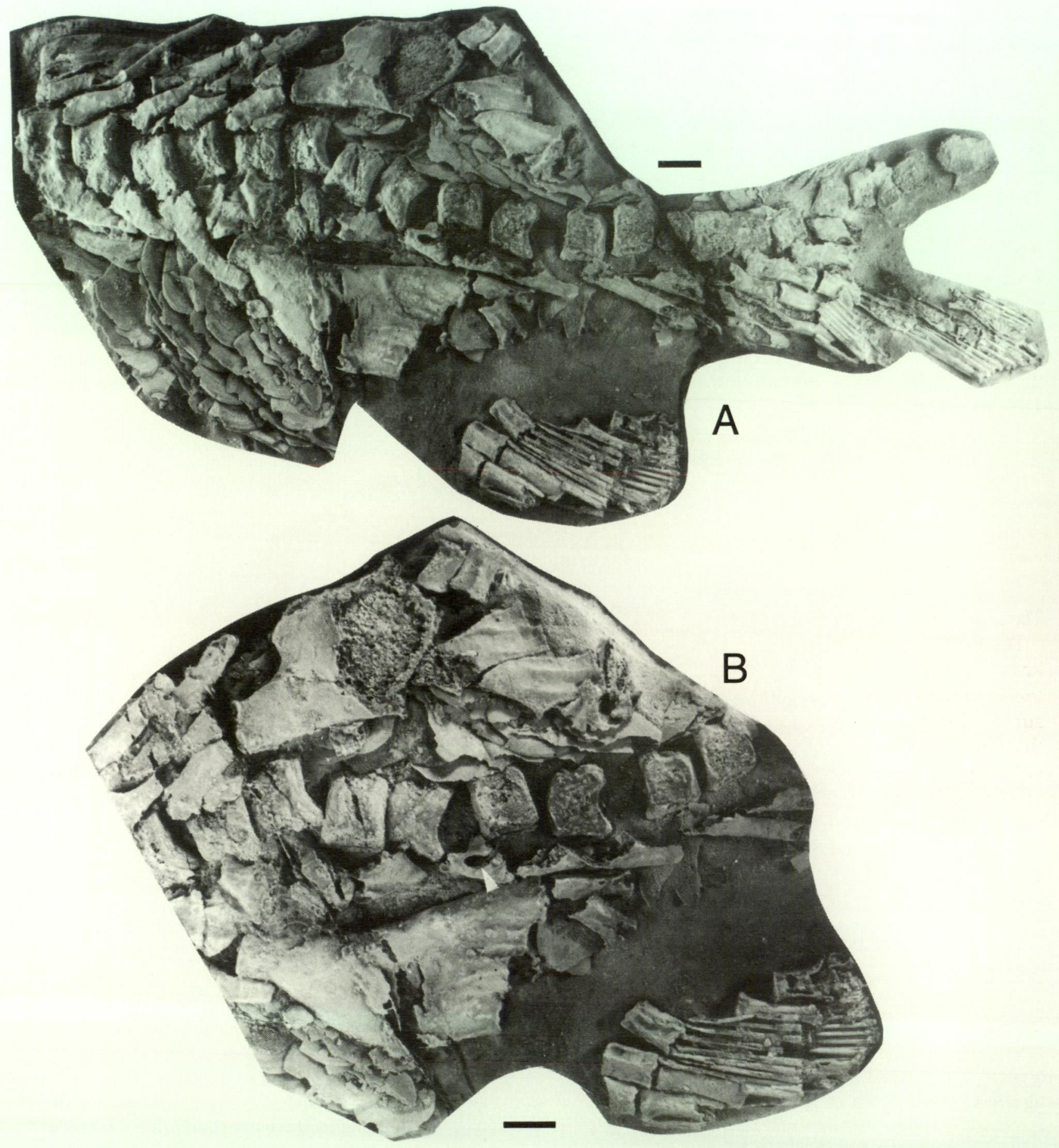

Figure 2 Two views of ANU 49114. B is enlarged to show details of the second dorsal and the anal fins. Note that the third secondary support for the dorsal fin is broken, but is still present, the neural arches supporting the main dorsal fin support is bifid, and the shapes of the haemal arches dorsal to the main anal fin support are broken but show short processes and one has a foramina (arrow) for a branch of the caudal artery to exit. Scales $=10 \mathrm{~mm}$.

tissue in the axis of which is a small perforation which runs the length of the block. In juveniles, and in the small centra in the caudal region mentioned above, the cavity is proportionately larger. On ANU 49116, the cavity is $1.4 \mathrm{~mm}$ in diameter in a centrum $6.5 \mathrm{~mm}$ in maximum diameter, whereas the more anterior centra on other larger specimens have cavities $0.7 \mathrm{~mm}$ wide in bones $13 \mathrm{~mm}$ maximum diameter.

The caudal region of ANU 49116 shows considerable variation in the length of the centra. As shown in Figure 1, the lengths of a series of centra (in $\mathrm{mm}$ ) from posterior to anterior is 6.9, 6.5, 7.0, 6.0, 4.8, gap, 3.9, 4.6, gap, 3.0, 4.2. Despite this 
variation, there is a general reduction in the lengths of the centra, towards the posterior, as well as a relative increase in the size of the central perforations. No centra from the tip of the caudal region are available. Although the fourth last centrum preserved has a strong haemal arch preserved, the subsequent ones do not have arches. They must have been lost during preservation.

A second specimen with a long run of centra is ANU 49114, but it is not so well preserved (Figure $2 \mathrm{~A}, \mathrm{~B})$. The more posterior centra were lost by erosion before the specimen was collected.

WAM 86.9.651 includes vertebra from the posterior end of a young specimen, and some of these have haemal arches attached (Figure $3 \mathrm{P}, \mathrm{Q}$ ). The advantage of these specimens is that they show isolated features which are lost when the centra are still joined together. This specimen also shows variation of the length of the centra, and this is not correlated with their diameter.

Other centra will be dealt with as we deal with other aspects of the skeleton.

\section{The First Three Centra}

The first centrum has no evidence of a rib. It is known from only one individual (ANU 35645), but the surface of the centrum shows no sign of a surface for the attachment of a rib. The second and third centra show a small break in the surface on each side of the specimen, and this has been interpreted as indicating the attachment of ribs (Campbell and Barwick 1988, figures 34-36). The nature of this attachment shows up as a small scar low down on the side of the centrum, and they may indicate where the ribs themselves, or less possibly the sites of a parapophosis, were loosely attached. Assuming that the scar represents the original attachment point, the ribs would have pointed posteroventrally. These ribs are well preserved and are figured below (Figures $4 \mathrm{D}-\mathrm{F} ; 5$ ).

The first centrum has a convex anterior face. Each subsequent centrum is amphicoelous, but has a small median cavity to transmit the notochord. No articulatory facets break the continuity of the anterior and posterior margins of the centra. The first three centra lie close together, and their lateral margins are deeply excavated. On the external surface, the axis of the centrum is covered with a shiny layer of tissue, and its edges are prominent (Campbell and Barwick 1988, figures 34B, 36A). These edges mark the boundary of intercentral capsules which contain the fluid of the joints. The space between them is occupied by laminar tissue which forms the articulatory surfaces of the centra. The shiny tissue carries the ventral nerve root ventrally as was shown by Campbell and Barwick (1988, figure 36). It contains large numbers of pores, some isolated and others joined by grooves. The surfaces on the centra are placed together and would limit lateral movement (Campbell and Barwick 1988, figures 34-36). Such movement would not have been expected, judging from the the arrangement of the neural arches which cross the boundaries of the centra and have loose attachments to adjacent neural arches.

\section{The Pleural Centra}

The number of rib bearing units remains unknown, but it must have been at least twenty. The best preserved material comes from WAM 86.9 625 (Figures 12 A,B) and WAM 86.9.650 (Figures 10 $A, C, E)$, which provided most of the centra which were sectioned. The posterior centra are more elongate than the first three described above, and though most of their lateral walls are covered with a perichondral layer of bone, the anterior and posterior edges of this perichondral bone do not stand out to form a sharp edge (Figures $7 \mathrm{E} ; 10 \mathrm{~B}$ D) against what must have been a connective intercentral capsule. The margins of the centra where they contact one another, consists of finer grained porous bone making a narrow band, and this can be seen on ground surfaces and in thin sections to be the more recently added layers of tissue (Figure $12 \mathrm{~A}-\mathrm{C}$ ). These must have been deposited in sequence against the soft tissue occupying the space between the centra.

On the ventrolateral sides of each centrum is a well developed parapophysis (Figures $7 \mathrm{C} ; 10 \mathrm{~A}-\mathrm{C}$; 11), which is the ossified version of the basiventral cartilage found in extant dipnoans. This is fused to the centrum (Figure $14 \mathrm{~A}$ ), but the junction between this and the centrum can be distinguished by a suture which is not continuous. The degree of fusion varies from specimen to specimen, and in some individuals the paraphophysis falls free from the centrum. Usually the junction is best seen on the posterior and the ventral faces, because the anterior face has a covering of periosteal material.

Each parapophysis is flat or slightly concave at its base. The ventral surface has lightly impressed radial markings which have the appearance of muscle attachments (Figure $7 \mathrm{C}$ ). In dorsal view, the anterior end of the parapophysis is turned backwards at $25^{\circ}$ to the median line. The front face of the process is also flattened and meets the base in a slightly rounded angle. The posterior face is naturally much shorter than the others, and is distinctly concave.

The terminus of the parapophysis is almost triangular, but its dorsal edge has a slightly rounded extremity as is best shown on WAM 86.9.650 (Figures 9;10). This attachment surface lies almost vertically, but the details are hard to find in an uneroded condition. Some complete ones are oriented at an angle of about $70^{\circ}$ to the axial line, indicating that the ribs must have had a strong posterior orientation. Vascular bone occupies much 


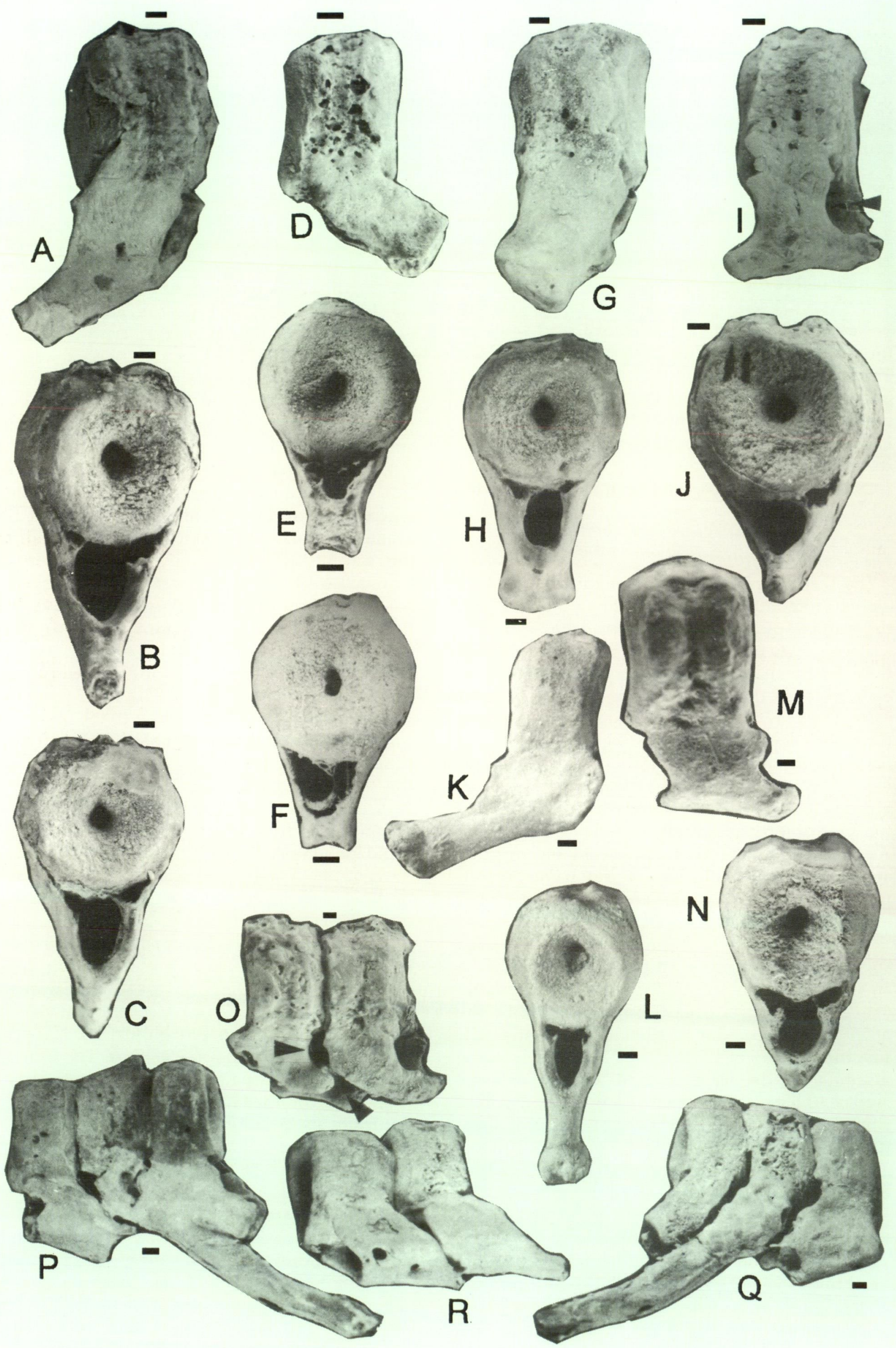


of the parapophysis, and can be seen to be made of unbroken bubbles of bone. Its terminus fits precisely with the end of a rib.

Between the two parapophyses on a centrum, the basal surface of the centra are distinctly concave longitudinally and laterally (Figure $7 \mathrm{C}$ ). The surface apparently was covered by a thin layer of periosteal bone, some of which has been removed during preservation and preparation, to expose the coarse vesicular tissue of the centra. This cavity would have housed the upper part of the haemal system.

\section{The Centra Posterior to the Body Cavity}

These are known from several specimens (Figures $10 \mathrm{~A}-\mathrm{C} ; 11)$. The neural arches are not well preserved and usually fall free. The haemal arches are discussed below. ANU 49116 shows centra well along the caudal fin and these have long haemal arches. It is not known if these arches continue to the extremity of the caudal region. All the centra are small, circular in cross section, have a disproportionately large foramen for the notochord, and are relatively shorter in comparison with their width in the more posterior positions.

One small specimen, ANU 35641, is available and has several centra preserved. Some of these are only $4 \mathrm{~mm}$ in diameter, but show that the concavities in both fore and aft faces are deep, and the opening in the middle of the centrum is relatively large (Figure 12 D).

Specimens of the posterior centra of the small specimen ANU 49262 are illustrated in Figures 12 $D, E ; 13 A, B$. Of course, rib parapophysis are not present on these specimens and they have neither neural nor haemal arches. It is assumed that they therefore come from a posterior position in the animal. The canal for the notochord is large with respect to the diameter of the centrum, and the amphicoelous faces are deep. Details of the internal structure are shown, and these are very similar to those of the more anterior centra. Photographs of the centra are shown in Figures $12 \mathrm{D}, \mathrm{E} ; 15 \mathrm{~A}, \mathrm{~B}$, and these indicate that the concentric layering of the inner structure is more regular than those of the pleural centra. Nevertheless the concentric layers are connected by struts, and a large number of perforations occur in the laminae. Thin sections show that the central part of the centrum is composed of poorly defined tissue, probably ossified cartilage.

\section{Histology of the Centra}

Sections of pleural centra of adult specimens have been cut longitudinally and obliquely along the central notochordal axis, and vertically especially through the parapophysis. Most of these sections have been cut from WAM 86.6.650 (Figures 13 C,E$\mathrm{G} ; 14 \mathrm{~A}-\mathrm{C}$ ) and another from ANU 49284 (13 A,B; $15 \mathrm{~A}, \mathrm{~B})$. The centra from posterior to the anal fin from a Paddys Valley, Gogo specimen, now ANU 49262, was sectioned to show the formation of an individual which has a large notochordal opening. The specimens were partly etched with acetic acid before sectioning, so that the orientation of the sections could be determined. The result of this is that it is possible to examine the tissue still embedded in matrix as well as embedded in the plastic impregnating solution. The only work on Devonian dipnoans with which we can make comparisons is that of Schultze (1970) where he wrote on Griphognathus sculpta Schultze, Jarvikia artica Lehman, and ?Soederberghia. Of these, the work on G. sculpta is the more complete. The structure of the small posterior centra are described first because they show the early stages of development of the centra.

\section{Small Posterior Centra}

In vertical section, the small posterior centra of ANU 49262, show the space around the notochordal opening occupied by poorly organised tissue which contains a large number of spaces filled with a black substance. We interpret these as infilled cartilagenous cell spaces. In places the tissue contains oval shaped openings, and these show up best in crossed polars (Figure $15 \mathrm{~A}, \mathrm{~B}$ ). This is reminiscent of the section of $G$. sculpta figured by Schultze (1970, Plate 39, figure 1a). At large magnifications (Figure 13 D) the tissue shows weak concentric lineations, and along these the black cartilagenous cell spaces are aligned.

This axial zone passes laterally into the concentric

Figure 3 Centra and haemal spines from a specimen WAM 86.9.651, in which most of the units have become separated. All specimens show the notochordal canal, the large opening for the caudal artery, and the two smaller openings for the caudal veins. The position for each unit can be identified by reference to Figure 1 and Figure $10 \mathrm{D}$. A-C. Lateral, posterior and anterior views of an element from the anterior end of the caudal fin. D-F. Same three views of a more caudal element. G, H. Lateral and anterior views of an even more caudal element. I, J. Lateral and posterior views of a unit from dorsal to the main anal fin support. K, L. Lateral and posterior views of a posterior caudal unit. M, N. Lateral and posterior of a unit dorsal to the main anal fin support. This specimen has been partly broken. O. Two units from anterior to the anal fin. A large foramen (arrowed) carries a branch of the caudal artery. P, Q. Two views of three caudal units showing distortion. The haemal arches are almost complete, but the middle one is joined to the posterior one on one side and has a caudal radial attached to it. $R$. Two units from even further forward of the anal fin, the anterior unit having two openings that enter the caudal artery canal. This specimen has been partly broken. Scales $=1 \mathrm{~mm}$. 


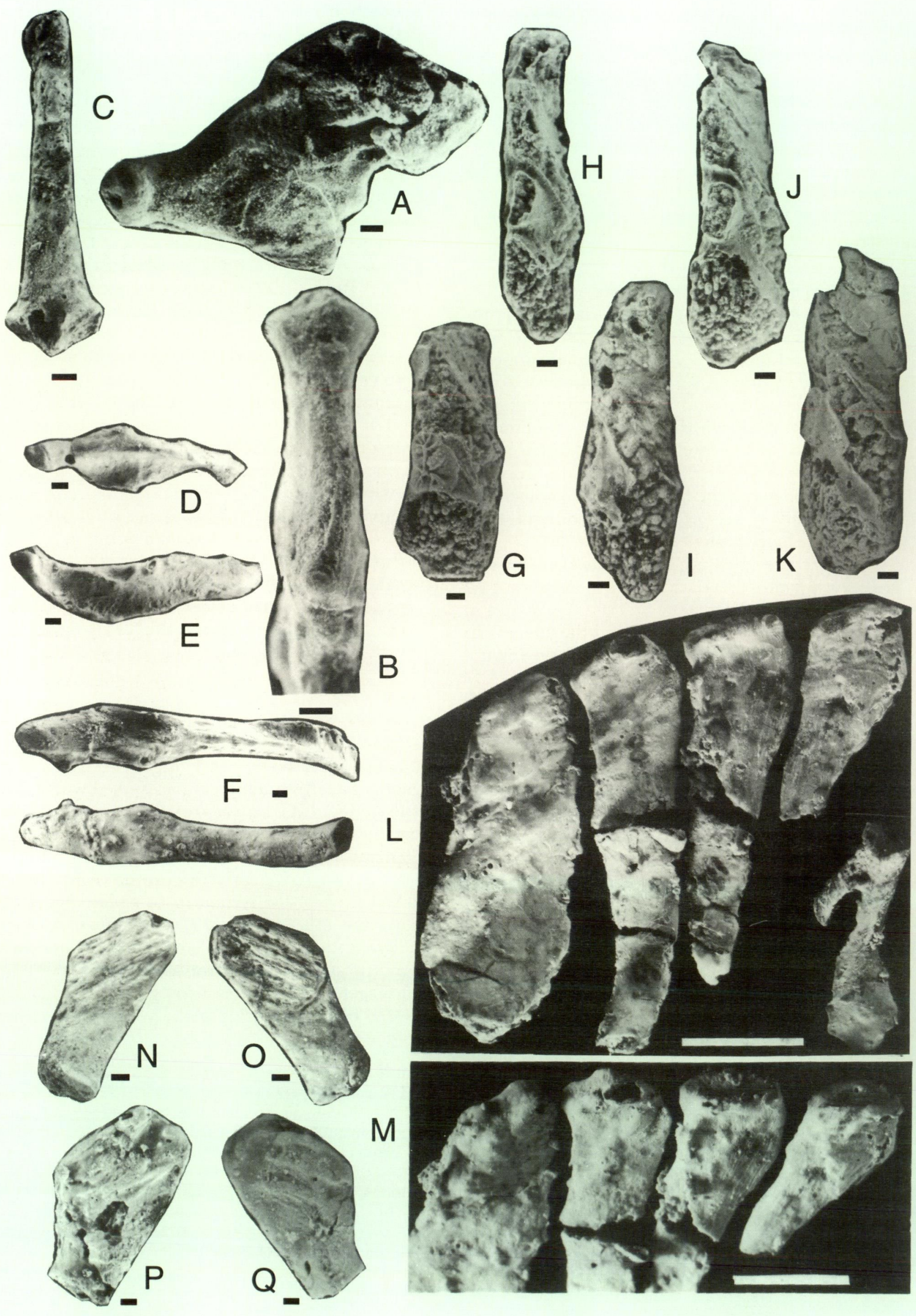




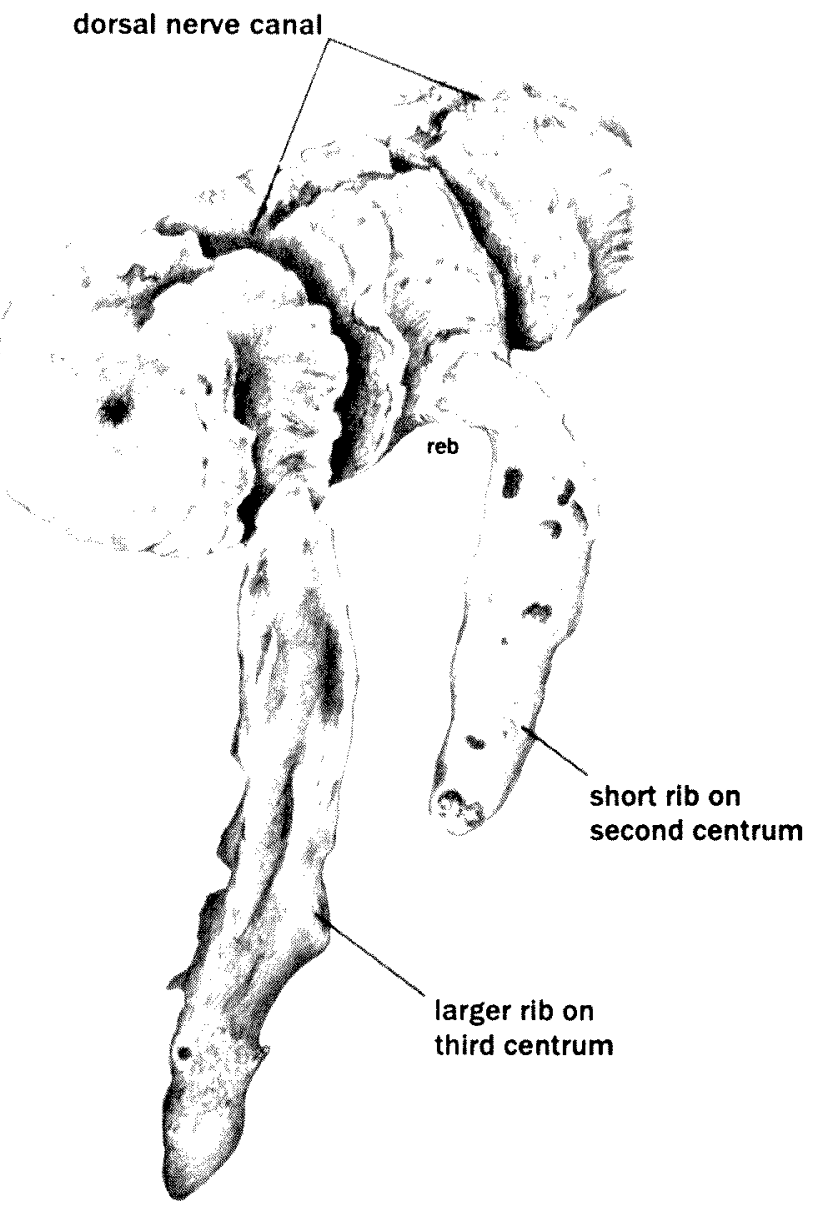

Figure 5 The three most anterior vertebrae of ANU 35645 in posterior view, drawn to show the sharp-edged perichondral layer surrounding the centra. The rib orientation is taken from the shapes of the attachment surfaces of the ribs. No rib was attached to the first centrum.

lamellae which form the bulk of the centra. Between the lamellae the spaces which are now open would have been filled with cartilage in the living animal. Each lamella has a core of calcified cartilage with large black cell spaces, and this is surrounded by a thin layer of laminated tissue which lines the open spaces through the centrum.

The outermost layer of the centrum is not well developed. It consists of very finely laminated tissue, which in places has a botryoidal surface. It is comparable with the thicker material described below for the pleural centra.

In longitudinal sections the axis is composed of the same tissue described above. This continues around the articulating faces and the lateral parts of the centra (Figure $13 \mathrm{~A}, \mathrm{~B}$ ). Branches of this material extend into the laminae that make up the bulk of the centrum, and it is clear that at this stage of the development of the centra there is continuity between the tissue forming the amphicoelous surfaces and the laminae of the main body. Growth lines indicate that the new material is added concentrically to the whole centrum.

\section{Pleural Centra}

The pleural centra have also been cut vertically and horizontally. They are bounded by a shiny layer of tissue which we have referred to as perichondral. The reason for this is that it encompasses the lateral parts of the centrum which would have been made of cartilage originally. Thin sections show that in places it lies on bone but elsewhere it is on calcified cartilage. This layer contains many perforations for nutrient canals. In thin sections the layer is made of fine-grained closely spaced layers which is organised into spherical or domed patterns, and in places the surface is botryoidal (Figure $13 \mathrm{C}, \mathrm{D}$ ). It contains no osteocyte spaces. During growth this layer must have been resorbed and a new layer redeposited subsequently.

The horizontal section of a large specimen shows that the bones consist of two types. 1 . The main part of the centrum is made of elongate bony layers running parallel with the lateral margins. These layers contain abundant osteocyte spaces. Polished surfaces (Figure $12 \mathrm{~A}-\mathrm{C}$ ) show that the elongate bony layers are partly in sheets and partly in tubes of bone. These tubes are circular in places but in others they are elongate, and ovate in cross section. Variation in size is great, and layers are often interconnected. This is easily seen in oblique views of a polished surface, and in cross section (Figure 14

Figure 4 A, B. Lateral and dorsal views of the main support of the second dorsal fin from WAM 86.9.651. The dorsal view is enlarged to show the left-right bifacial terminus. Part of this specimen has been broken. C. Anterior view of a proximal supraneural with the terminus that fitted into the concave surface on the neural spine. Same specimen. D, E. The ribs from the second centrum photographed in different orientations, from ANU 35645. F. Rib from the third centrum of same specimen, viewed from both sides. The lower of the two figures shows the attachment surface. G. An isolated half of a neural arch with the crest broken. H, I. Another half of a neural spine, $\mathrm{H}$ being slightly rotated to show the split of the dorsal nerve into two units. J, K. Similar views of another arch. Specimens G-K from ANU 49900. L. Reassembled supraneural spines from WAM 86.9.625. The original specimen is photographed on Figure $21 \mathrm{~A}, \mathrm{~B}$. A broken neural arch is shown on the bottom right with its crest well preserved. M. Slightly tilted crests of same to show the groove along the crest with nodes along their margins. N, O. A supraneural spine from ANU 49900, photographed from both sides. $\mathrm{P}, \mathrm{Q}$ adjacent spines from the same specimen. Note the fine grooves on both sides of each specimen, but particularly on $N$ and $O$. Scales $A-K=1 \mathrm{~mm} ; \mathrm{L}, \mathrm{M}=10 \mathrm{~mm} ; \mathrm{N}-\mathrm{Q}=1 \mathrm{~mm}$. 

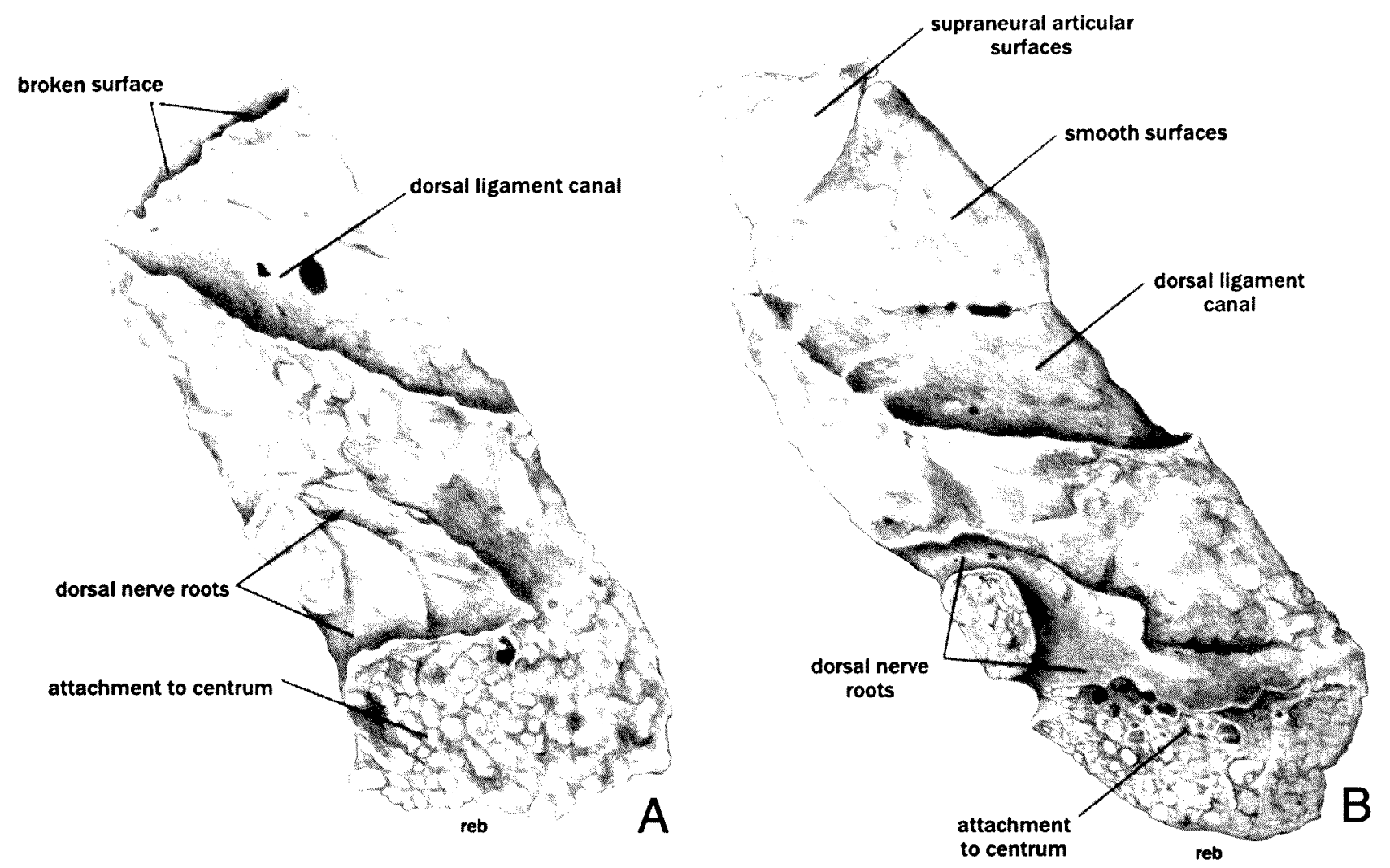

Figure 6 The neural arches consist of left and right units which readily fall apart on ANU 49900. A, B. These two figures are drawn from a slightly posterior view of two left arches to show the passage of the dorsal neural nerve which splits into two branches. Compare with Figs $4 \mathrm{H}, \mathrm{J}$. The surface dorsal to the furrow for the ligament is smooth, but the most dorsal part is where the two sides of the arch join beneath the surface for the proximal neural spine.

A,B). The thin sections show the discontinuity of the bony layers as the cut surface runs into and out of the discontinuous tubes and sheets. 2. The concave surfaces facing the adjacent centra are composed of cancellar bone forming a strengthening band. This layer runs into the corners of the centrum and usually forms an edge which projects lateral to the marginal perichondral layer. Medially it forms part of the wall of the axial canal (Figure $12 \mathrm{~A}$ ). This material was deposited from the soft tissue occupying the space around the notochord, which must have contained cells capable of depositing bony tissue.

Vertical sections (Figure $14 \mathrm{~A}-\mathrm{C}$ ), show concentric layers of the bones in Type 1 above, and many new details are revealed. The elongate bony layers are two sided and in places are thin banded. Within a single bony layer where the the two sides separate (Figure $14 \mathrm{~B}$ ), a dark layer of material is present This seems to be made of opaque material within which it is sometimes possible to identify single units. From some of these it is possible to recognise thin dark fibrils which extend into the surrounding bone. In other places the lamellae in the bone can be seen to grade into the dark tissue. From this we conclude that the dark material is partly calcified cartilage which grades laterally into the junction between the two layers of bone. Sections through the tubular part of the tissue show a dark core which also represents the calcified cartilage around which the bone was deposited.

Long thin canals of perichondral bone run deeply into the centrum (Figures 13 F,G; $14 \mathrm{~A}$ ) and other oblique canals are common. These are the inward extension of the nutrient canals noted in the lateral walls of the centrum.

In addition, the above sections of $G$. whitei have passed through the parapophysis on the ventrolateral edges of the centra. As indicated in the section on the gross structure, the boundary between the parapophysis and the centrum is best shown on the ventral and posterior margins. The dorsal edge is well joined to the centrum. The thin sections are oblique to the parapophysis and pass anteriorly to the junction with the ribs. The whole surface cut is surrounded by a continuous bone layer which is thickest on the dorsal side. Close to the junction with the centrum the dorsal layer thickens and is composed of parallel fibres at right angles to its surface and with numerous osteocyte spaces. The contact with the centrum remains secure and rarely in specimens does it open up. The 


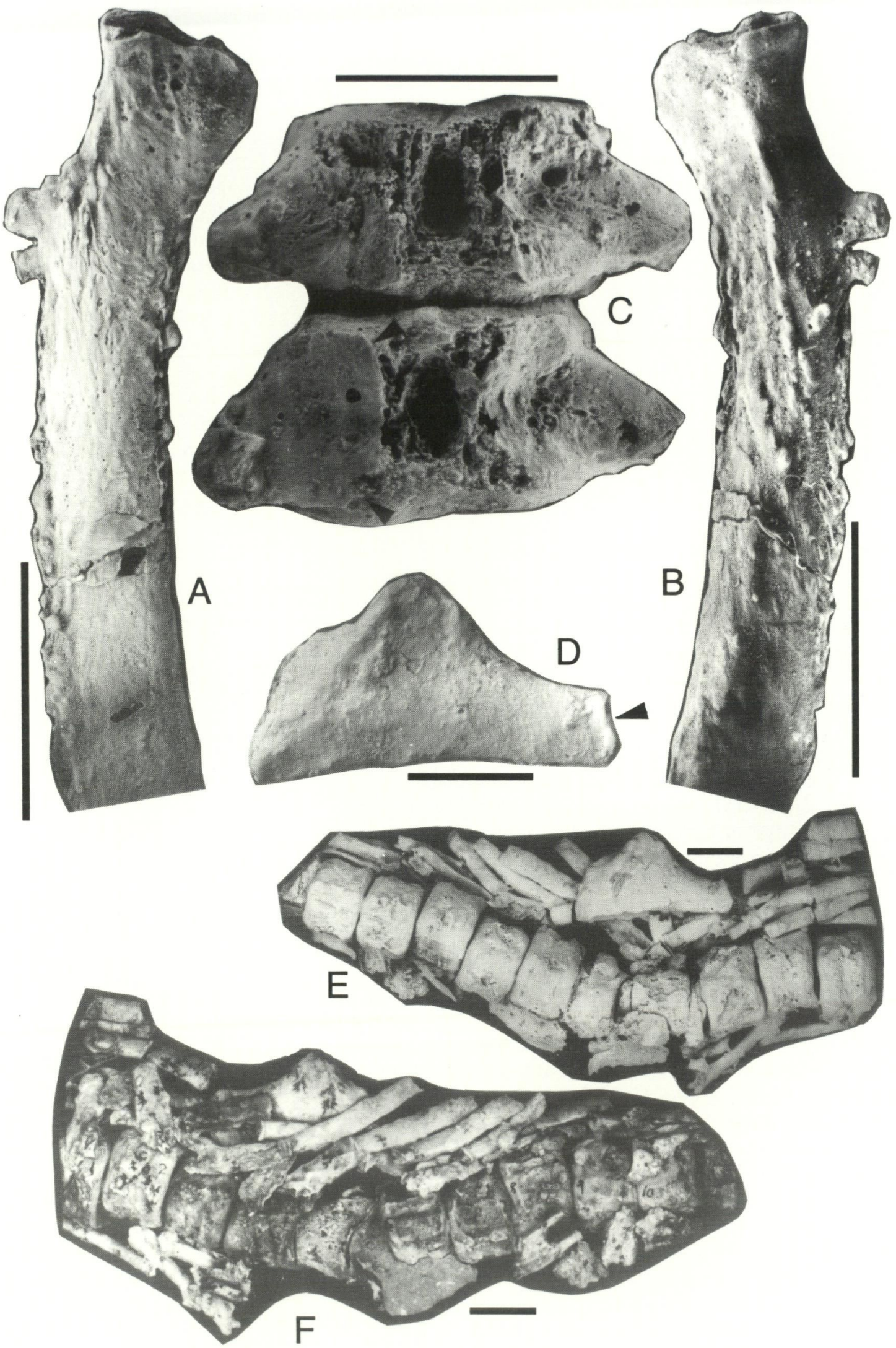

Figure 7 A, B. Medial and lateral views of an isolated rib showing the detailed sculpture on their surfaces and the nodes along the lateral faces. WAM 86.9.650. C. Ventral view of two centra showing the posterolaterally directed parapophyses, and their sharp junction with the centrum (arrowed). The deep medial cavity is dorsal to the haemal canal. ANU 49115. D. Lateral view of the anterior dorsal fin support. Note the dorsoventral shape of the attachment to the neural arch (arrowed). WAM 86.9.645. E, F. The original specimen from which Figure D was obtained. Note the elongate neural arch which is broken through, the elongate proximal supraneural spines which have flat termini for the distal supraneural spines. Scales $=10 \mathrm{~mm}$. 


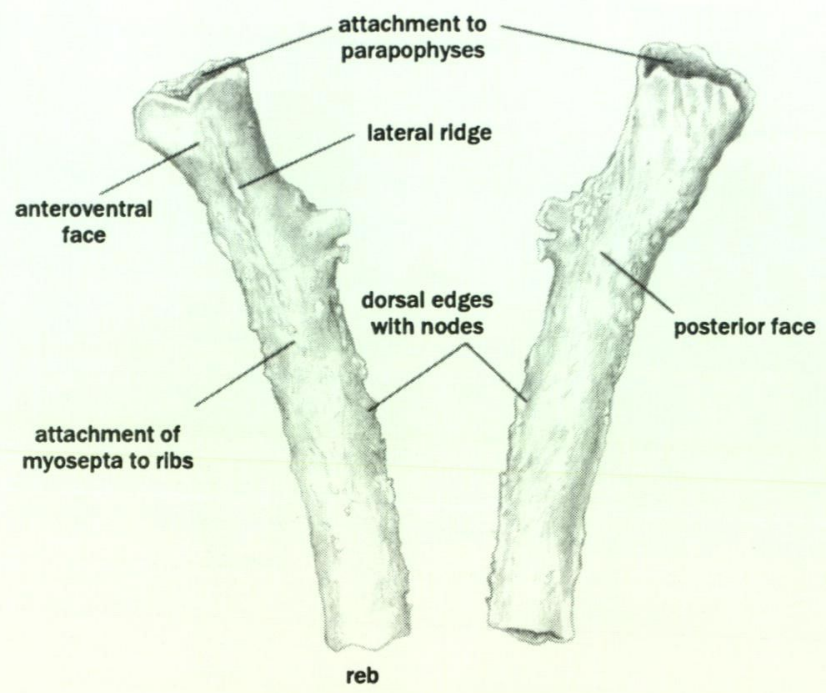

Figure 8 Drawings of the rib illustrated on Figure $7 \mathrm{~A}$, $B$, with the elements labelled.

ventral edge is thin bone and fades away in places.

Internally the parapophysis contains widely spaced bony layers. In places these are joined to the bones making up the concentric layers of the centrum, and no sharp boundary is visible. These bony layers are thin and discontinuous (Figure 14 A), indicating that they were in process of resorption and redevelopment during growth. This was apparently necessary because the junction between the ribs and the parapophyses is so open that movement along this junction must have been possible. The passage of an occasional bony layer across the junction would still allow small movement to take place especially if it was not anchored at either end.

\section{Summary}

From these two sets of data we conclude that the early growth stages were rapidly ossified forming a strip of hard tissue around which the perichondral layer was deposited. Following this the perichondral layer was resorbed, and expansion took place by the formation of lamellae to increase the diameter. The margins of the centrum were formed of the ossified cartilagenous layer. Next the space for the notochord was relatively reduced, and the ossification of the cartilage forming the lamellae took place by the addition of layers of clear bone on their surfaces. This process continued until most of the laminae had been ossified. The thick interfacial surfaces were added to independently in the adult stages, and the continuity between these layers of this tissue and that of the body lamellae was lost. In addition, the lamellae were formed laterally at the margin of the centrum and the ossified cartilage was replaced by the lamellae. At the core of the centrum, ossified cartilage was converted to endochondral bone.

\section{Ribs}

As indicated above, no cranial ribs have been found in this species.

In this discussion we mention the most anterior ribs on the free centra. On the second centrum which is only $13 \mathrm{~mm}$ in diameter, the ribs are only $16 \mathrm{~mm}$ long (Figure $4 \mathrm{D}, \mathrm{E}$ ). They have a modified triangular cross section over most of their length, and are thickest medially. The sharp edges of the ribs have some nodes similar to those of the major ribs. The third centrum has ribs $28 \mathrm{~mm}$ long (Figures 4 F; 5), but these are not so uniform as the first ribs in shape, although they are largely triangular in cross section.

The pleural ribs are well preserved. The details of their positions along the column are not known at present, but ANU 49116 shows that the centra up to ten in front of the second dorsal fin do not have a parapophysis for rib attachment. Another badly distorted specimen (ANU 49282) has 16 rib-bearing

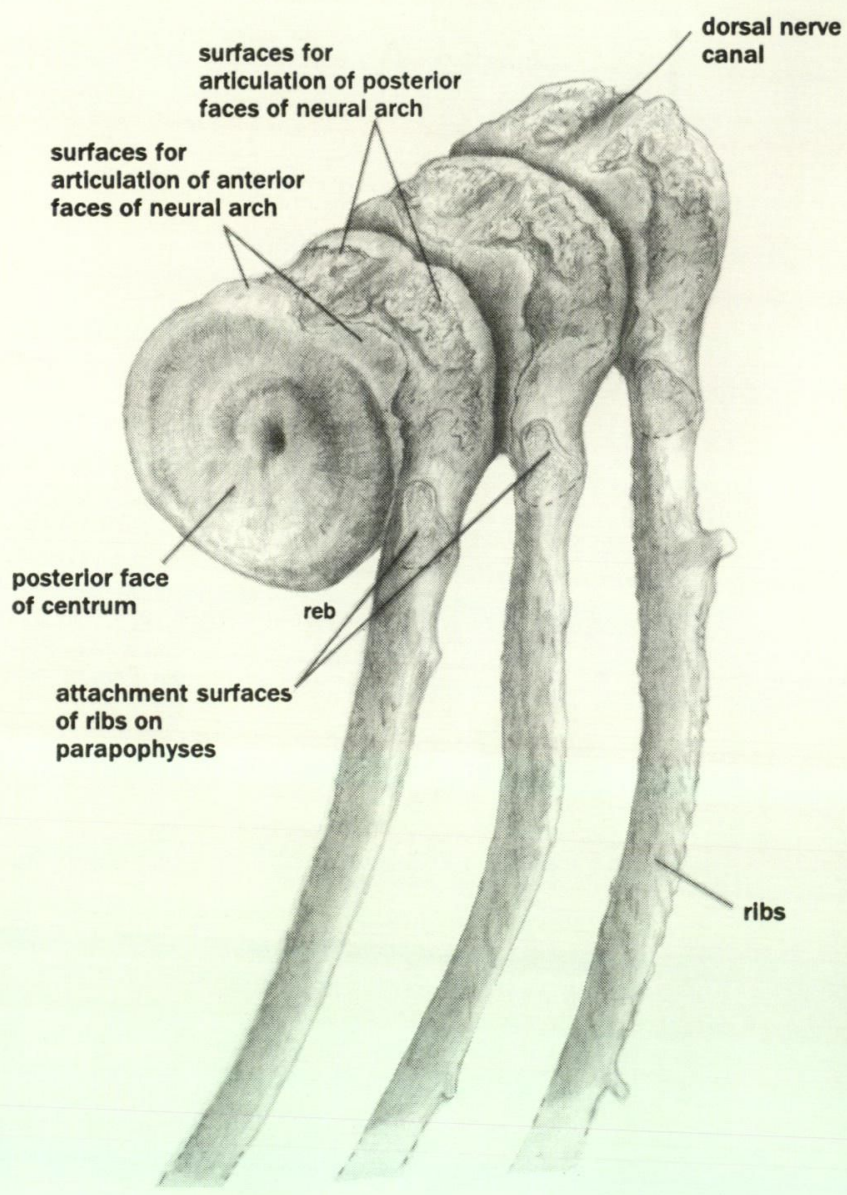

Figure 9 Posterior view of a reconstruction of three pleural ribs in position on the centra. The neural canal and the notochordal canals shown. The attachment of the neural arches to the centra, and the canal for the ventral nerve, are clear. The shapes of the attachment surfaces to the parapophysis are shown in outline as though the ribs were transparent. WAM 86.9.650. 

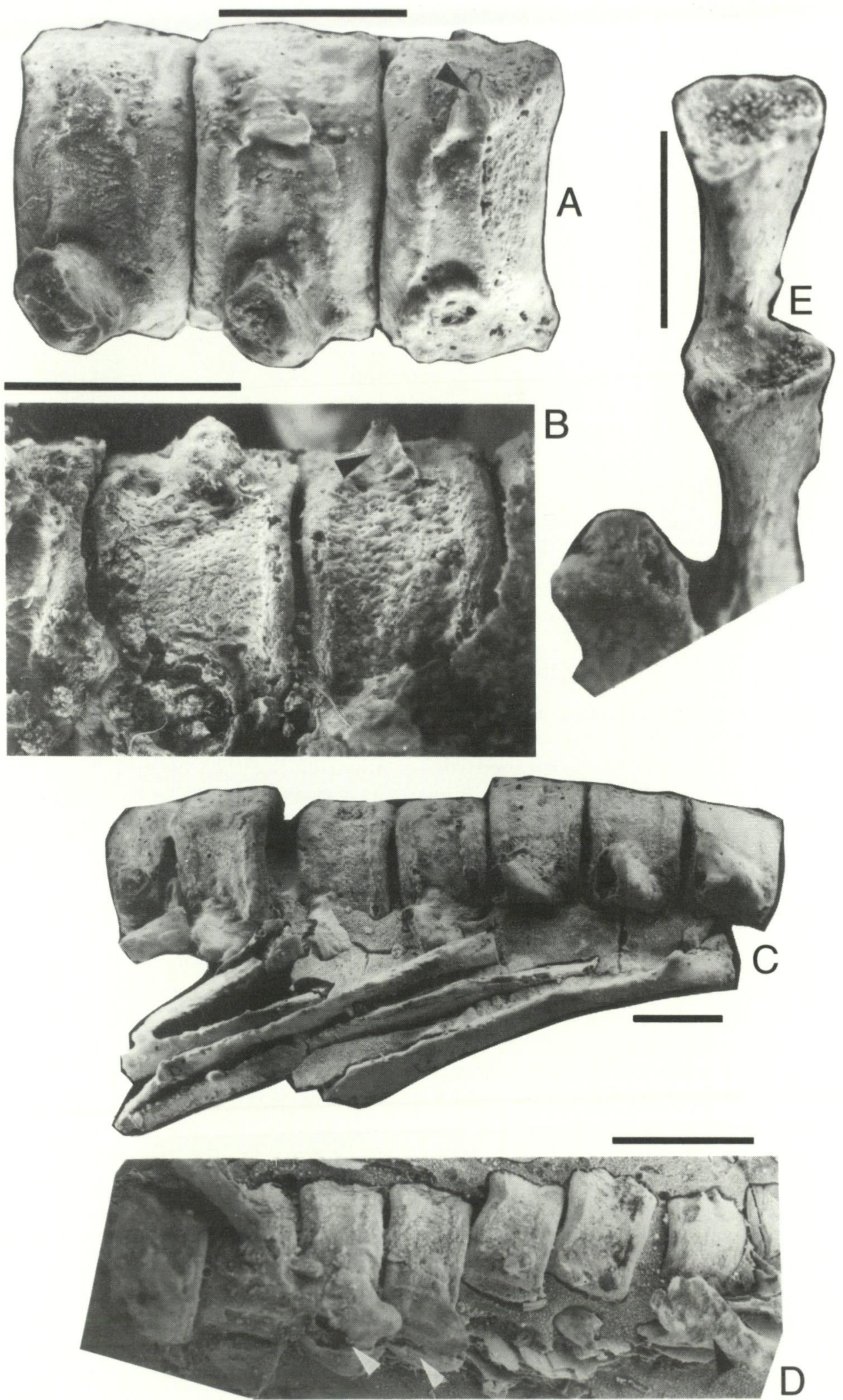

Figure 10 A. Lateral view of three pleural ribs showing the parapophyses for the ribs, the narrow perichondral layer, and the canal for the ventral nerve (arrowed). Anterior edge of the first centrum (right) eroded. WAM 86.9.650. B. Centra from ANU 49900, showing the unworn surface with finely punctate perichondral surface, the narrow bands of bone forming the junction with the adjacent centra, and the canal for the ventral nerve (arrowed). Anterior to the left. C. ANU 49900. Centra with the ribs present but slightly displaced. D. Part of the vertebral column of ANU 49207 dorsal to the anal fin. White arrows show the haemal arches short and posteriorly directed. Black arrow shows the first of the haemal arches with a longer spine, coming from the position posterior to the fin support. E. WAM 86.9.650. The attachment ends of three ribs showing the shapes and the conchoidal attachment surfaces of their cores. 


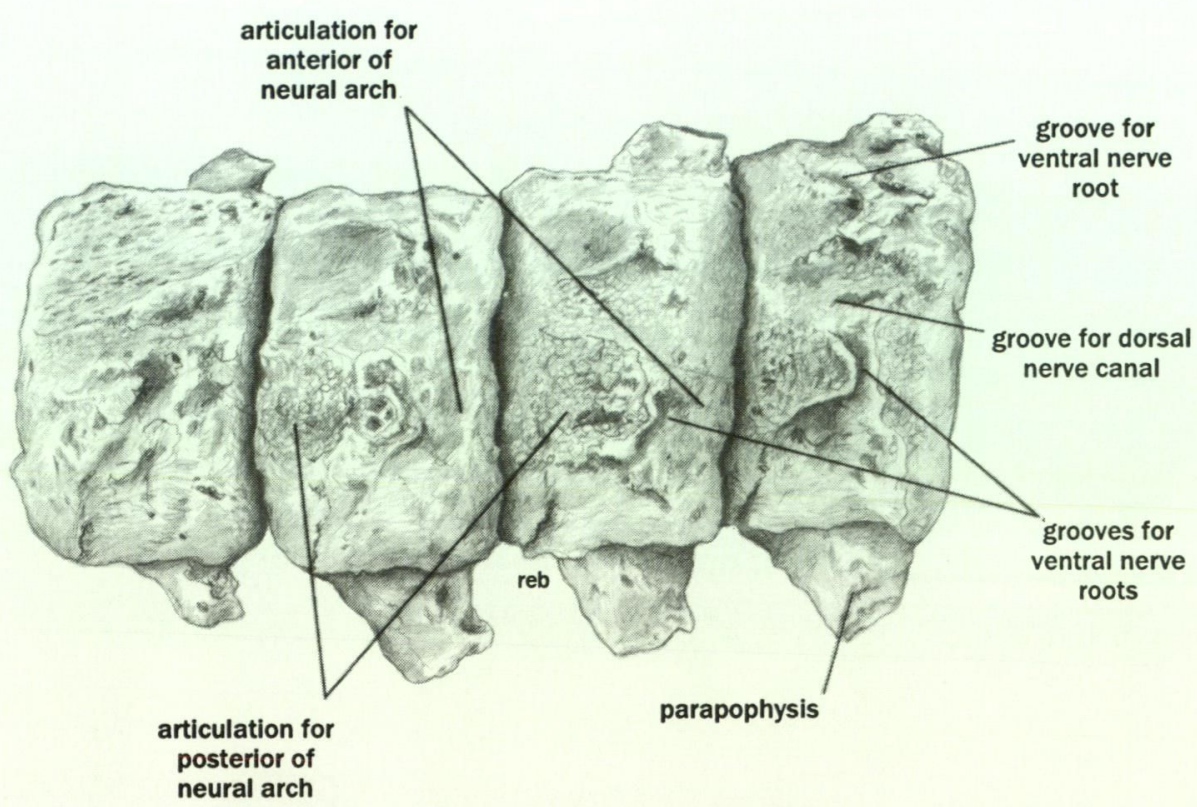

Figure 11 Slightly tilted dorsal view of four pleural centra from ANU 49115 to show the neural canal, the ventral nerve canal, and the areas of attachment of the neural arches. Note the large posterior attachment lying anterior to the ventral nerve canal, and the much more diffuse attachment posterior to the ventral nerve canal.

centra passing back to centra with a strong haemal arch.

The pleural ribs are directed postero-ventrolaterally at an angle of about $70^{\circ}$ to the axial line. The axes of the proximal parts of the ribs are almost straight, but lateral to that they are gently bent. Restored to their approximate position on the end of the parapophysis, the ribs project posterolaterally and then curve posteroventrally (Figure $10 \mathrm{C}$ ). The body shape must have been narrow in the region of the body cavity.

In cross section the ribs are sub-triangular proximally, and are slightly grooved on their surfaces (Figs 7 A,B; 8 A,B; 10 A,E) producing a pattern that meets the ends of the parapophysis. The deepest groove is on the posterior side of the rib. Lateral to the dorsal edge, the surface of the rib has a short flattened surface which dies out against the strong dorsal ridge. The lateral ridge is very variable in shape, in some it is rounded and in others it is low but sharp, with elongate ridges along its crest. The ventral edge is sharp and often carries flat elongated nodes. As the lateral ridge dies out distally, the lateral face of the rib becomes domed and then flat. The median face is also flat so that in adults the distal cross section of the ribs is ovate. In adults the proximal parts of the lateral and internal surfaces of the ribs are covered with fine linear markings. These probably represent the attachment surfaces to the myosepta which shows how the flexure of the body cavity was accommodated.

The attachment of the ribs to the parapophysis was made of cartilage, and the evidence is that it was a mobile junction. Thus, although the centra were relatively rigid with a limited amount of movement possible from the point of view of body flexure, the ribs would have been capable of movement independently of the centra. This would account for the surface structure on the ribs described above. It would also account for the nodes on the ribs which possibly indicate points where the muscles of the myotomes acted from rib to rib.

The smaller specimens in the collection generally show the same structures as the adults, but they tend to be more rounded in cross section distally, and they have few markings on their surfaces.

We do not have any specimens with ribs in natural position, but the orientation of the articulation and the distal flattening of the ribs, indicates that the ribs ran posterolaterally and angled across as many as 10 segments as defined by the centra. The cross section of the body cavity is also known from the whole specimen AMF 72402, and this supports the proposition that the ribs have the shape described above.

\section{Haemal Arches}

\section{Arches Anterior to the Attachment of the Anal Fin}

On ANU 49114 (Figure 16H) the anal fin is approximately in position. This shows three haemal spines in front of the anal fin attachment. They are curved posteroventrally, and the one anterior to the fin is bent around the anterior end of the anal fin support (Figure $2 \mathrm{~A}$ ). The two anterior to it are shorter and are more acute at their tips. All three arches have small incomplete ends to which 

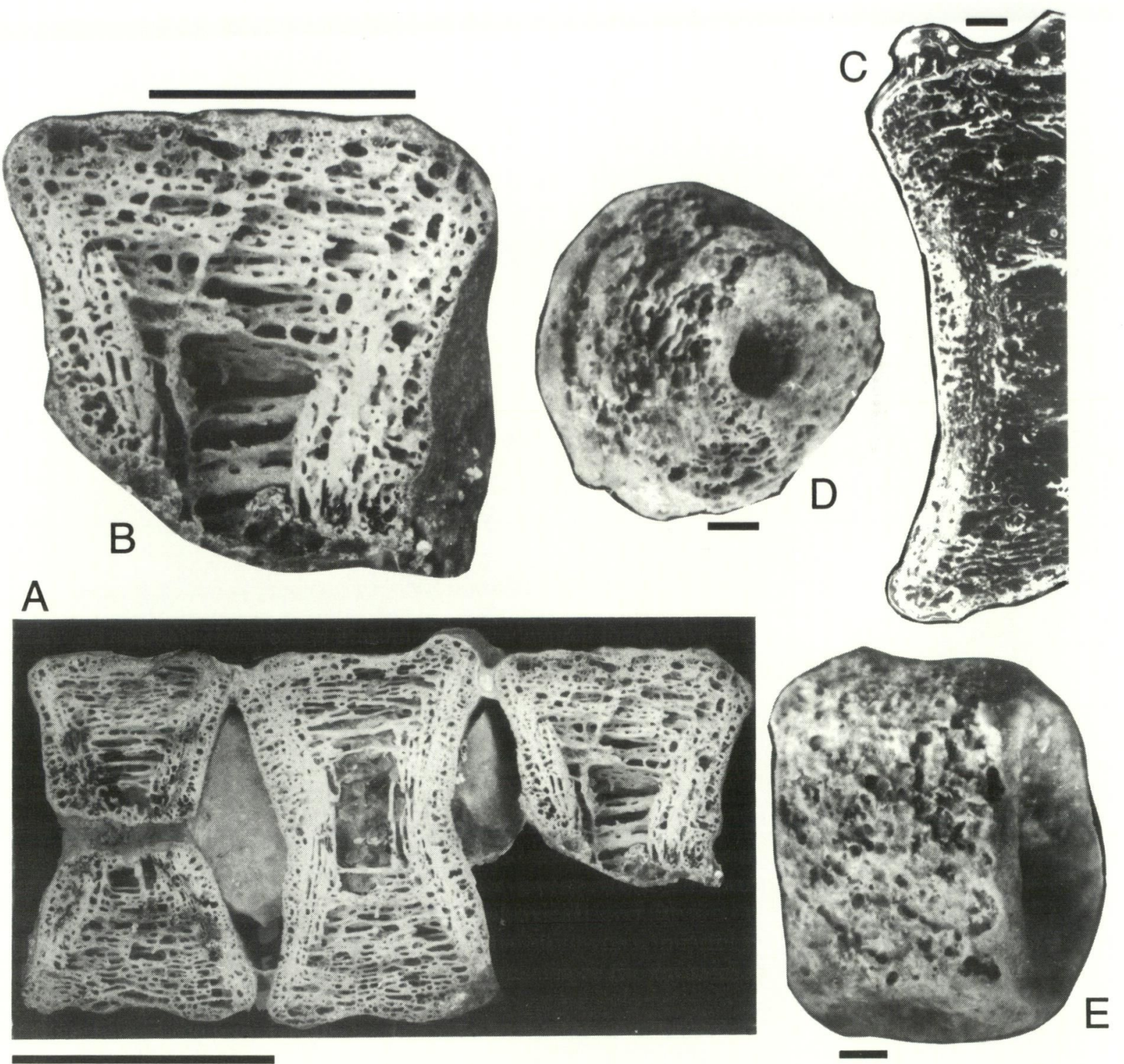

Figure 12 A. Two and a half centra cut on a polishing wheel to show their internal structure. The left section passes through the notochordal canal, but the other two are off centre. Note the difference in structure between the tissue forming the bulk of the centra and the tissue forming the intra-central surfaces. WAM 86.9.625. B. Enlargement of the centrum on the right showing the details of the internal structure. C. Thin section of WAM 86.9.650 showing details of relationships between the marginal sheath and the deeper bony tissue. D. An obliquely worn small posterior centrum from ANU 49262, showing the change in tissue between the central and the marginal layers. (cf Figure E). E. Laterally worn specimen from the same individual as Figure D showing the small blister-like ossified cartilage forming the marginal layers. Scales A, B = $10 \mathrm{~mm}$; $\mathrm{C}-\mathrm{E}=1 \mathrm{~mm}$.

proximal haemal spines must have been attached. The most posterior one is preserved and is $4 \mathrm{~mm}$ long. The anterior faces of the haemal arches have a shallow groove into which the spine anterior to it would fit. The main fin support is attached to the axial column by a short straight haemal arch.

ANU 49120 has five centra anterior to the anal fin attachment (Figure 16H). Only the most posterior one has the full haemal arch present, and the others are broken. No proximal haemal spines are preserved, and the one anterior to the anal arch has a complete terminus showing that no spine was present.
ANU 49116 (Figure 1) does not show the attachment of the anal fin to the haemal arch which supported it, but it does have an approximate position for the second dorsal fin which lies opposite the attachment of the anal fin in other specimens. This is an important point because it allows us to estimate the position of the posterior end of the body cavity. At least eight of the centra in front of the attachment have some haemal arches present, although they are all broken.

WAM 86.9.651 has isolated vertebrae from the posterior half of a specimen, and judging from the 

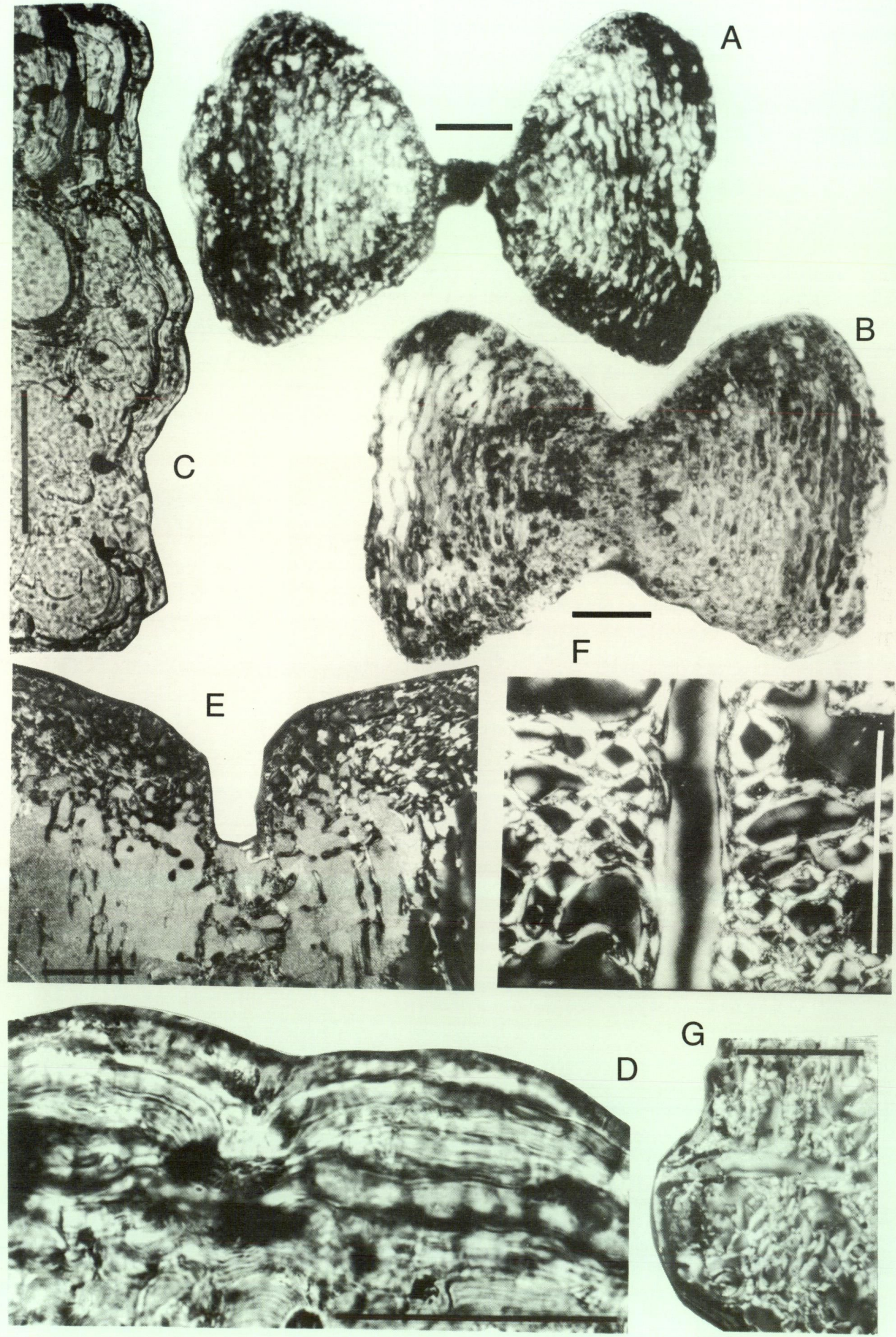
fact that some of them have short haemal spines turned sharply backwards and have a small space for the attachment surface for a tiny proximal haemal spine such as occurs in ANU 49114, we consider that they are from the area anterior to the anal fin. Two of these have vertebrae still in association. One has a large ventral opening through the haemal spine and enters posteriorly into the large central cavity in the arch (Figures 3 $\mathrm{O})$, the other has lateral openings (Figure $3 \mathrm{I}$ ). Some of these openings were at first thought to be gaps in the wall resulting from preparation, but further investigation shows that they are genuine openings. Still other arches have small openings irregularly scattered over their surfaces, and entering the haemal canal (Figure $3 \mathrm{R}$ ). These seem to be openings for the circulation of the blood into the posterior part of the body. Similar openings are present on one of the arches on ANU 49116.

\section{Arches Posterior to the Anal Fin Attachment}

ANU49114 has six depressed arches posterior to the anal fin. The sixth is somewhat longer than the others. This pattern allows for the anal fin to be pushed up close to the body. The seventh is broken by a crack in the rock, but it was much longer than the sixth, and it may have had an subhaemal spine, but this is not determinable because of the crack. The terminus of the seventh is well rounded and shows no sign of a further attachment. The eighth is also badly broken, but it has lepidotrichs attached to its terminus, and has more subsequent haemal arches which are short and followed by radials with lepidotrichs. Presumably the eighth is the first of the caudal series. Figures 19 A, B have been reconstructed with a similar break.

On ANU 49120, four arches posterior to the attachment of the anal fin are depressed and bent backwards ventral to the haemal opening (Figure $16 \mathrm{H}$ ). The fifth arch is also bent, but it has a short subhaemal spine. The sixth is also short and bent, but it is incomplete.

WAM 86.9.651 has several posterior vertebrae preserved, and some of them are isolated. All were etched from a single block of rock, and presumably came from a single specimen. Some of the haemal arches are short and have no sign of subhaemal spines, so thay are probably from vertebrae 4 and 5 described above from ANU 49114. Some of these haemal arches have openings through the wall, and these do not have a regular arrangement. Some are small and others are almost as large as the canal itself. They open directly into the central canal. ANU 49116 has one haemal arch in this position (Figure 1B, marked with an arrow) and it has a large ventral opening in its wall. Other specimens show larger centra, and must come from the area anterior to the anal fin attachment, and have occasional large openings. Others are more elongate, have strong surfaces for the attachment of spines and represent the first of the caudal radials.

The internal structures of the haemal arches are best preserved on the isolated units from WAM 86.9.651. They are illustrated on Figure 3. A large central space occupies the central part of the arch. Its walls are thin, and they make a circuit around the central space, except for the surface against the centra. This canal would have carried the caudal artery. Lateral to the central space, and against the centrum on each side is a small tube which opens fore and aft, and was connected between vertebral units. They open laterally between the haemal arches, and presumably connected with the myotomes. These lateral canals would have carried caudal veins. Other veins would have been located laterally in the body. The structure of the centra is almost identical with that of Protopterus annectans Owen, as figured by Schultze (1970, plate 40, figure $1 \mathrm{a}, \mathrm{b})$.

\section{Arches in the Caudal Region}

These are best preserved on ANU 49116, but broken fragments also occur on ANU 49114 (Figures 1,2). Isolated elements also occur on WAM 86.9.651 (Figure 3). The arches on ANU 49116 do not show clearly where the first of the caudal arches occurs. We have placed it at the first element which has a terminus to which a caudal radial may have beeen attached. The lepidotrichs are not preserved in this region, and so they cannot be used to support our interpretation. The arches decrease in length after the first two. The more anterior arches 3 to 8 have concave distal termini, indicating that the radials attached to them were able to move

Figure 13 A. Longitudinal section through a small centrum ANU 49262, cutting through the notochordal canal. Dark material is hard tissue. Note that the fine vesicular material (ossified cartilage) extends from the axial region around the entire surface enveloping the elongate bony layers of the central region. $\mathrm{B}$. A second section from the same specimen cut off-centre. C. Thin section through the marginal perichondral layer of WAM 86.9.650 showing concentric banding overlying spherical banding. D. Part of the perichondral layer on the vertical layer of ANU 49262. E. Part of a longitudinal section through WAM 86.9.650, the upper part being through the notochordal canal, and the lower passing off-centre. Note the fine ossified cartilage across the top surface, and the elongate bony tissue embedded in limestone forming the lower part of the section. F. Section through one of the canals in the bone of WAM 86.9.650 showing the continuous layer tissue along its margins. G. Section through the margin of WAM 86.9 .650 longitudinal section showing the canal in the outer ossified cartilage. Scales $=1 \mathrm{~mm}$. 

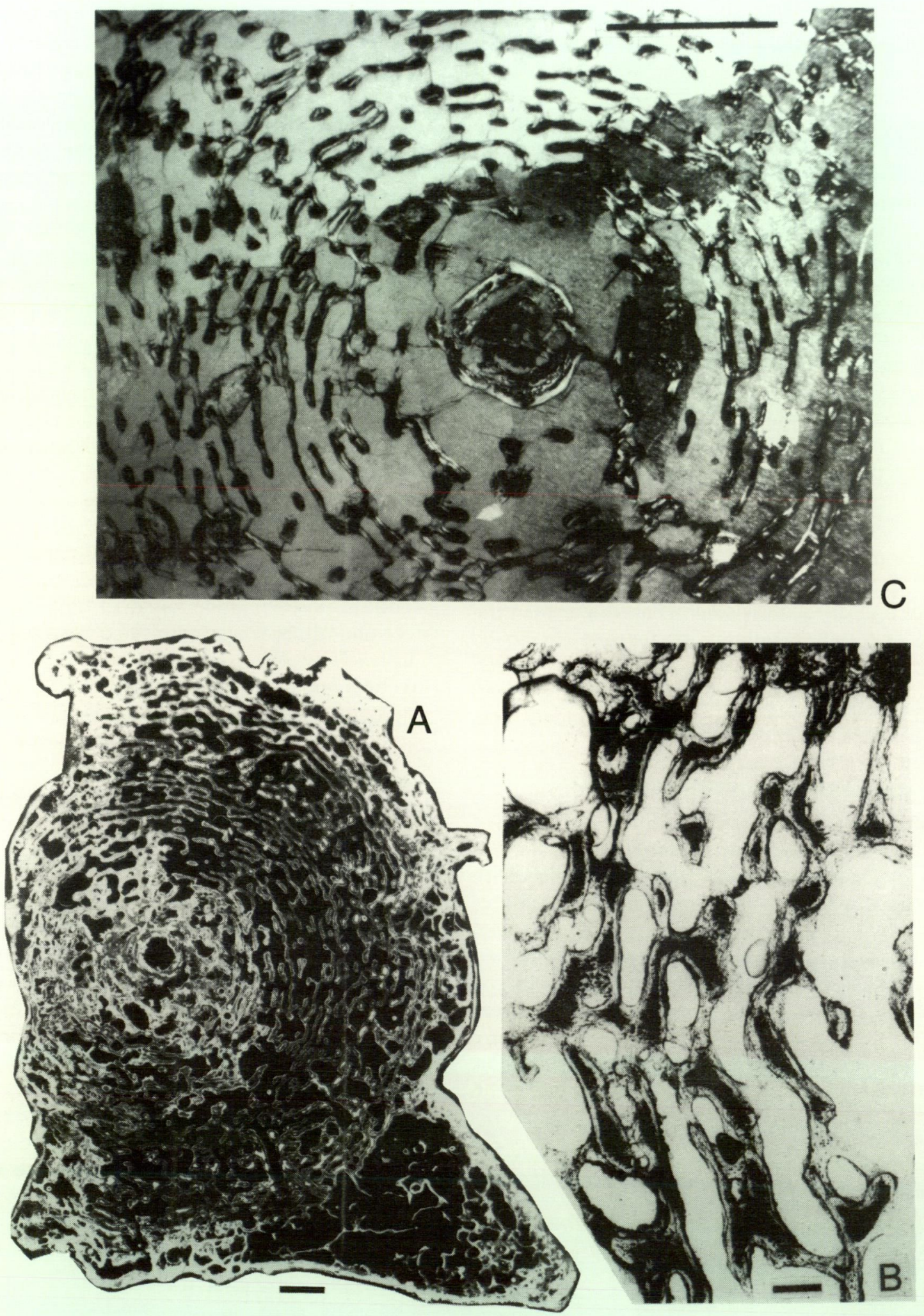

Figure 14 A. An incomplete vertical section produced by printing the section itself on photographic paper. The light coloured material is hard tissue, and the dark is open space. The bony tissue contains small spaces containing dark material. Note the notochordal canal surrounded by irregular ossified cartilage, and then by elongate layers of bone. The parapophysis contains an open meshwork of bone which does not make continuous layers. The outer layer on the parapophysis is thicker on the dorsal side and makes a strong junction with the centrum. B. Enlarged thin section of the same specimen with the light spaces being gaps. Layers of light tissue is bone surrounding dark ossified cartilage. C. Axial section around a central notochordal canal. Limestone still occupies the matrix throughout. Note the narrow space occupied by ossified cartilage passing laterally into more or less concentric bony layers. All sections from WAM 86.9.650. Scales $\mathrm{A}, \mathrm{C}=1 \mathrm{~mm}$ and $\mathrm{B}=0.1 \mathrm{~mm}$. 
laterally. The first two arches are more slender than those following, and their termini are rounded rather than concave. All the preserved arches have grooves down the posterior faces and weaker ones on the anterior faces, again allowing lateral movement to take place.

Judging from the shapes displayed on ANU 49116, we have determined that some of the units obtained from WAM 86.9.651 came from the caudal region. These are illustrated on Figure 3 D-F, G,H, all of which have a divided space at the end of the haemal arch. Figure $3 \mathrm{~A}-\mathrm{C}, \mathrm{K}, \mathrm{L}$ and $\mathrm{P}, \mathrm{Q}$, were from the front of the caudal region, each with a long arch and an undivided tip.

\section{Neural Arches}

\section{Arches on the Anterior Centra}

The first few arches are well preserved on ANU 35645. They have been described by Campbell and Barwick (1988), commented upon by Campbell and Barwick (1999), and they have been illustrated in both of these papers. The most significant points are:

1. the arch has an attachment to centra in front and behind;

2. each is attached to the neural arch in front;

3. short sharp supraneural processes are directed laterally;

4. the dorsal and ventral nerves can be clearly traced;

5. the first neural arch is depressed and shows no sign of a dorsal surface like those on subsequent arches.

These structures suggest that the anterior part of the vertebral column was rather inflexible, and the dorsal and ventral nerves passed through well defined gaps in the bone.

\section{Arches on the More Posterior Centra}

In more posterior vertebrae, most neural arches are broken off from the centra, but each was connected with two centra (Figures 7 F; 9; 10 A,B; 11). These connections were made of globular bony surfaces, without any evidence of fusion. Thus they would impede lateral movement at each junction, although this limitation would have been restricted. None of these more posterior neural arches shows an epineural spine such as those on the anterior arches.

The surfaces of the centra were partly destroyed by acid, and it is difficult to detect the details of the attachment surfaces of the neural arches. Occasionally, as on ANU 49115 and ANU 49900 (Figures $10 \mathrm{~A}, \mathrm{~B}$ ) which come from dorsal to the body cavity, the ventral nerve root is preserved between ridges of periosteal bone as in the anterior vertebrae (Campbell and Barwick 1988, figures 34 $\mathrm{B}, \mathrm{C} ; 36 \mathrm{~A})$. The surfaces adjacent to this groove, labelled $p$ ana and $a$ ana in the 1988 diagram, are not well preserved, but can be outlined on ANU 49900, ANU 49115, and less well on WAM 86.9.650 (Figures 10; 11). The posterior attachment of the neural arch is triangular in shape, and the anterior one is more ovate and is tucked in beneath the uplifted margins of the ventral nerve canal. The small individual ANU 35641, has more caudal
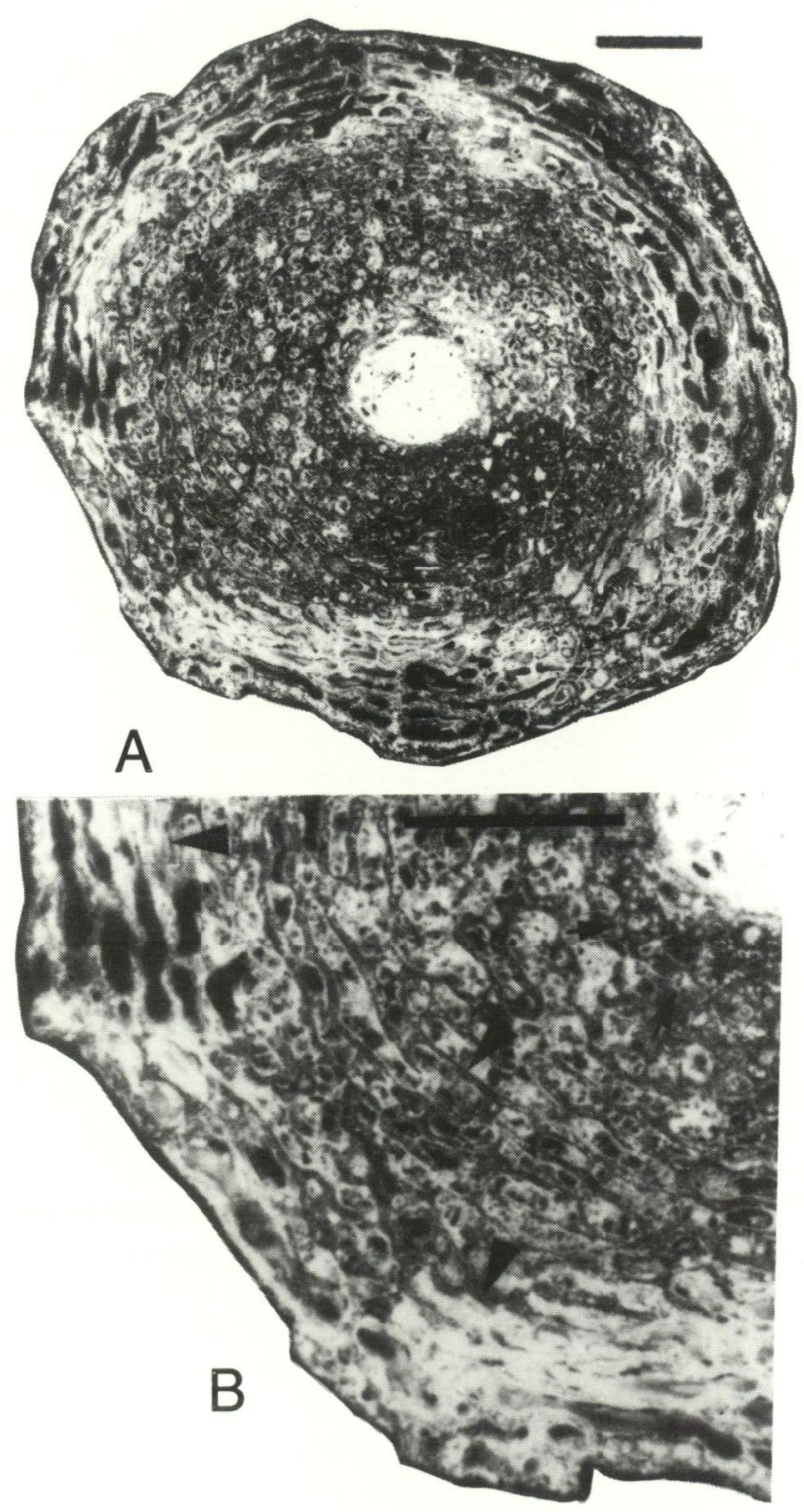

Figure 15 A. Vertical section through ANU 49262 showing the large space occupied by ossified cartilage around the notochordal canal. Central part of slide still contains limestone. Outer elements with elongate bony layers. Thin section printed directly onto photographic print paper. B. Electronic enlargement of Figure A showing more detail of the hard tissue, and the transition from ossified cartilage (small black arrows), to the bony layers (large black arrows). Scales $=1 \mathrm{~mm}$. 


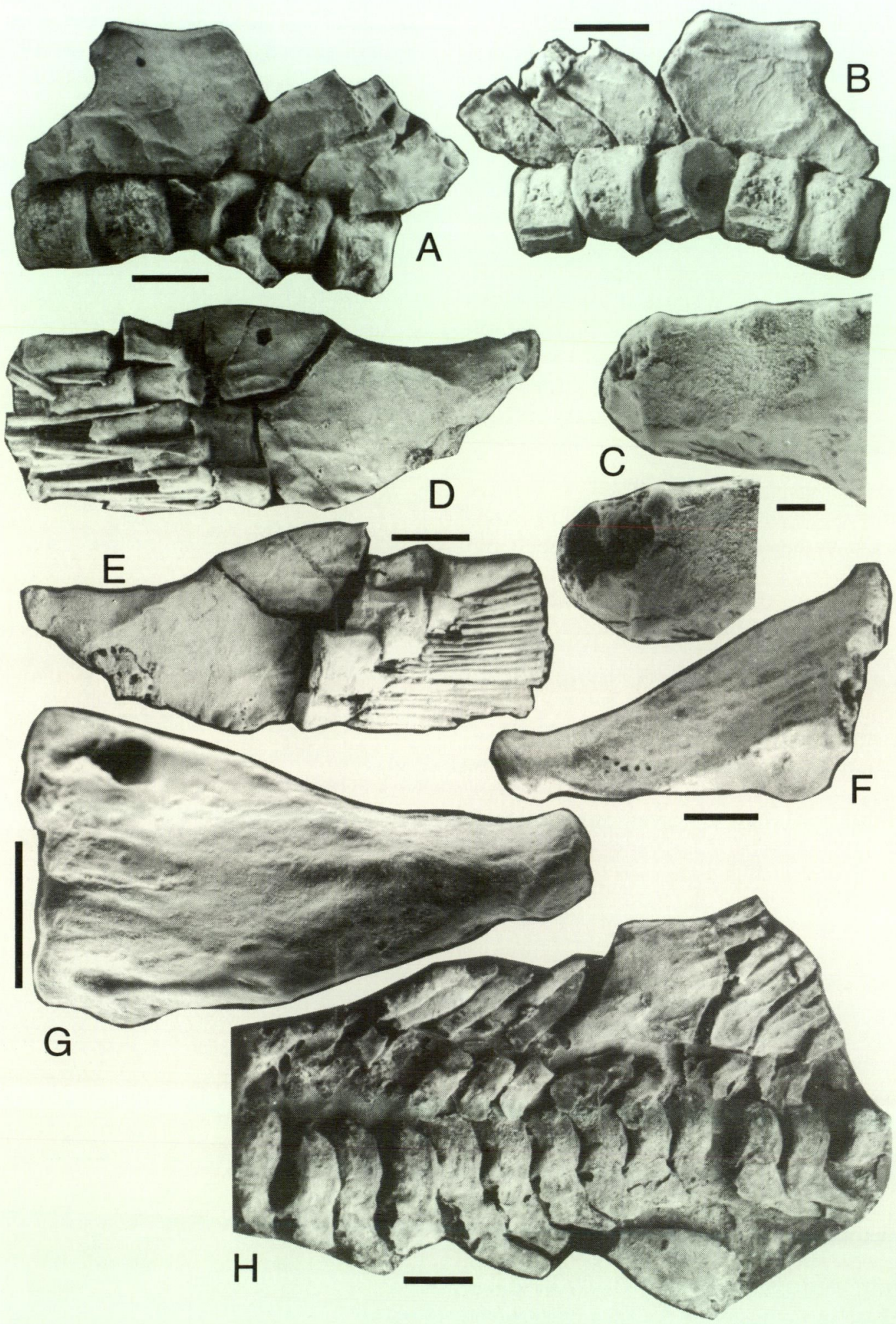

Figure 16 A, B. The second dorsal fin photographed from both sides of WAM 86.9.645. C. The tip of the main support structure showing the dorsoventral bifacial attachment and the muscle scars for the movement of the support. The lower of the two views shows the terminus in anterodorsal view showing the broken left-right bifacial face indicating left-right movement also. D, E. The two sides of the anal fin of WAM 86.9.645. Note especially the sharp ridge separating the area where muscle attachment occurs, cf. Figure $1 \mathrm{~F}, \mathrm{G}$. Much enlarged isolated main anal support structure of WAM 86.9. 651. Figure F is a slightly oblique view showing the broad flat surface on the posteroventral edge. The row of small dots is from the impregnating solution. G. Opposite side of same enlarged to show the muscle attachment for the muscles which move the radials. H. View of ANU 49120. Second dorsal fin well preserved. The neural arches and the proximal supraneural spines, and the neural arches anterior to and posterior to the anal fin, all preserved. Main support for the anal fin partly preserved and pushed posteriorly from its attachment. Main support for the second dorsal fin also pushed posteriorly. (For reconstruction see Figure $17 \mathrm{C}$ ). Scales A, B and D-H = $10 \mathrm{~mm} . \mathrm{C}=1 \mathrm{~mm}$. 
vertebrae, and an occasional specimen also shows the groove for the ventral nerve cord, and the areas adjacent to it are also small.

Traces of the dorsal nerve canals are visible on some broken arches, and they are not well enough preserved to be described. On the other hand, ANU 49900 has broken so that four of the neural arches have split down the midline exposing the nerve canals and the dorsal ligament canal. Three of these are well preserved, but the others have lost much of the periosteal lining on its inner face (Figures $4 \mathrm{G}-\mathrm{K} ; 6 \mathrm{~A}, \mathrm{~B}$ ). A pair of openings exit the dorsal edge on each side of the arch, and these join to make a single groove directed to the anteroventral corner, where it would join the dorsal nerve canal. These were for the two dorsal nerve canals which were described as entities in the first neural arches (Campbell and Barwick 1988, figures 34-36 ). A strong dorsal ligament canal occupies the surface dorsal to the two nerve canals, and dorsal to that the two sides of the arch are loosely joined together. The distal edge of the arch has two faces bent medially to which the supraneural bone was attached.

These same specimens show the attachment points of the two sides of the neural arches, and indicate why the two sides fall apart on etching. The surfaces of attachment to the centra are rounded bony surfaces indicating a loose cartilagenous connection. Between the two exits of the dorsal neural canals is an ovate surface with similar rounded bony surfaces, indication a connection between the two sides. Dorsal to the these canals, is a transverse strip which also contains similar bony plates, and these connect the two sides. Dorsal to the dorsal ligament canal there is an open space which may have contained an expansion of the dorsal ligament. Finally, the dorsal crest contains a junction which is strongest along the anterior edge where it is made of periosteal bone, but is also present between the two surfaces for the attachment of the supraneural bone, where it is made of small rounded bony surfaces. Although many points of attachment are present they are so weak that during preparation even slight pressure causes them to separate.

The dorsal surface of the centra shows only slight furrows where the neural cord passed along the surface. This is much smaller a groove than the one for the haemal canal.

\section{Supraneurals}

Specimen WAM 86.9.625 has some of the more anterior neural arches preserved. The most anterior part of the specimen available, Part $B$, has been photographed during preparation (Figure $21 \mathrm{~A}, \mathrm{~B}$ ), and after the arches have been separated by etching (Figure $4 \mathrm{~L}, \mathrm{M}$ ). Judging from the position of the preserved ribs and the shape of the neural arches, the anterior centrum preserved is probably just posterior to the three that were figured by Campbell and Barwick (1988, figures 34-36). The neural arches are thin-walled and are inclined to the axis. The most anterior supraneural element preserved is a large bone, flattened laterally, and with a groove along its crest. Posterior to this are three large distal supraneurals, each also having a similar groove along its crest. By aligning the groove along the crests of these distal supraneurals with that of the enlarged anterior distal supraneural, the relative positions of the elements can be determined. The large unit extends ventrally much further than the other three. Its ventral end it is slightly broken but it has the appearance of being attached to a smaller structure. The most anterior neural arch preserved in ANU 35645 has a small crest dorsal to the dorsal ligament canal, and an unformed surface for the attachment of the large element described above. The subsequent distal supraneurals also have slight grooves on their front margins which allow the elements to be aligned. The first two units have incomplete ventral ends at present, but they are well enough preserved on the original photographs. The supraneurals ventral to them have elongate dorsal edges which will match them. The third supraneural is complete, is much shorter than the others, and shows a rounded surface which would have provided an attachment for the supraneural below.

The longitudinal spacing of the supraneural elements cannot be determined from the specimen itself because they were not in position when etching occurred. However we note that on ANU 35645 , the second and third neural arches have dorsal surfaces to which supraneural elements were attached (Campbell and Barwick 1988, figures 3436 ), and it is quite clear that there were no gaps between the supraneurals. What is not clear is the possibility that the the large supraneurals may have been separated by smaller units. The specimen as preserved at present shows that lateral compression has taken place and that some of the neural arches have been pushed posteriorly. A solution to the problem of spacing depends on the discovery of a less distorted specimen.

As indicated above, the crests of the distal supraneurals are grooved. Along the edges of the grooves are slight eminences with sharp margins, and the surface of the distal supraneurals are slightly ridged beneath them. The whole surface gives the appearance of muscle attachment. This should be compared with specimen ANU 49900 described below. This is a most significant feature, suggesting that the crest of the distal supraneurals was attached to the connective tissue beneath the scales. Posterior to the four distal supraneurals just described, the neural elements are too poorly preserved to be described in detail, but it is clear 
that proximal supraneurals and short distal supraneurals, are present.

ANU 49900 is a partly disaggregated specimen with ribs attached to some of the centra. Apart from the ribs, two features of interest have been observed. Two isolated distal supraneurals like the large individuals described above in WAM 89.9.625, with a depression along their crests (Figure $4 \mathrm{~N}-\mathrm{Q}$ ), show the flanks well preserved and on these there are ridges which run parallel with the depression in the crest. These have the appearance of muscle attachment surfaces. The attachment end is planar.

The specimen ANU 49120 (Figure $16 \mathrm{H}$ ) shows the neural arches beneath the second dorsal fin, and the neural arches and supraneurals anterior to the fin which are more complete than those in other individuals. The arches ventral to the fin are depressed, inclined, pointed at their crests, and fit closely beneath the fin supports. The arches anterior to the fin are higher, concave on their crests, and support long thin proximal supraneurals. The one anterior to the main support is bent to fit into the curvature of the support, and has a sharp tip with no evidence of a distal radial. The second proximal supraneural is also pointed, but it curves slightly posteriorly at its tip. The third to fifth proximal neurals are of approximately the same length, and have tips which carried the distal supraneurals.

Four broken arches from anterior to the second dorsal fin are preserved on ANU 49114 (Figure 2 A). The neural arches are relatively short structures, approximately 1.5 times as long as the centra, and inclined at ca. $20^{\circ}$ to the axial column. They are surmounted by proximal supraneurals which are twice as long as the neural arches. They are oriented at the same angle as the neural arches, but some are curved slightly dorsally. The distal ends of the proximal supraneurals have an attachment surfaces for distal supraneural spine, but none of these spines is preserved on this specimen. These indicate that the dorsal surface of the body must have been high in this region leading up to the high second dorsal fin. It also implies that first dorsal fin must have been well forward of the second fin.

The specimen ANU 49116 (Figure 1) has the region in front of the second dorsal fin preserved, but the centra are all out of their proper orientation, neural arches have all been destroyed, and only the broken up supraneurals are present. These also show that the first dorsal fin must have been placed well forward. The proximal supraneurals have a double attachment to the neural arch indicating that they could move laterally on the dorsal surface of the neural arches, and the distal supraneurals have rounded distal tips.

WAM 86.9.645 (Figure 7 E,F) has a support for the anterior dorsal fin and a number of supraneurals posterior to it. The neural arches are long, and the proximal supraneurals are long and thin. They have a lateral bifacial junction with the neural arches as would be expected, and their distal tips are not complete indicating that distal supraneurals were present, but none of them are preserved in this specimen.

\section{Medial Fins}

\section{The Anal Fin Structure}

These are well known from four specimens. ANU 49114 is a large specimen with its centra anterior to the anal fins being approximately $130 \%$ greater in diameter than those in ANU 49116. The attachment of the anal fin is situated well forward of the anterior edge of the caudal fin. ANU 49114 shows that there were seven axial centra between the attachment of the anal fin and the first caudal fin segment. The other two specimens WAM 86.9.645 and 86.9.651, are incomplete but they show distinctive features, and will be discussed separately.

On ANU 49116 and 49114 (Figures 1; 2; 19 B) the main anal fin support is large, and flattened laterally but with distinct grooves running back to the surfaces which support the radials. The dorsal surface is concave in lateral view and gently convex in cross section. The ventral edge is convex in lateral view, and gently convex in cross section except at the posterior end, which has a broad flattened surface. However, the presence of lateral extensions on the grooved ventral surface suggests that muscles or ligaments were present and that these could have been vital for the movement of the lepidotrichs described above.

The main anal fin supports are strong structures which have a thick periosteal ossification over an open meshwork of struts. On ANU 49116, the attachment of the bone to the axial skeleton shows a bifacial vesicular surface, the ventral edge being turned backwards. On this same specimen, another plate, much smaller than the one just described, occupies its posterodorsal corner (Figures $1 \mathrm{~A} ; 18$ C). Its edge lies in line with the dorsal edge of the main anal plate. We refer to this plate as the secondary anal fin support. In this specimen the dorsal plate is isolated. In ANU 49114 the dorsal plate is fused to the main anal support plate, although the boundary between the two is clearly visible (Figure $2 \mathrm{~A}, \mathrm{~B}$ ). The surface of this dorsal plate carries radial ridges to the points of attachment of the radials, identical to those on the main anal fin support plate. The attachments for the radials form a stepped edge along the anal support plates. Three radials are attached to the main anal support plate, and three to the secondary plate. The proximal radials are strong plates with longitudinal ridges forming the corners of the plates. They expand slightly towards their posterior ends. It is not clear from these specimens if the proximal 

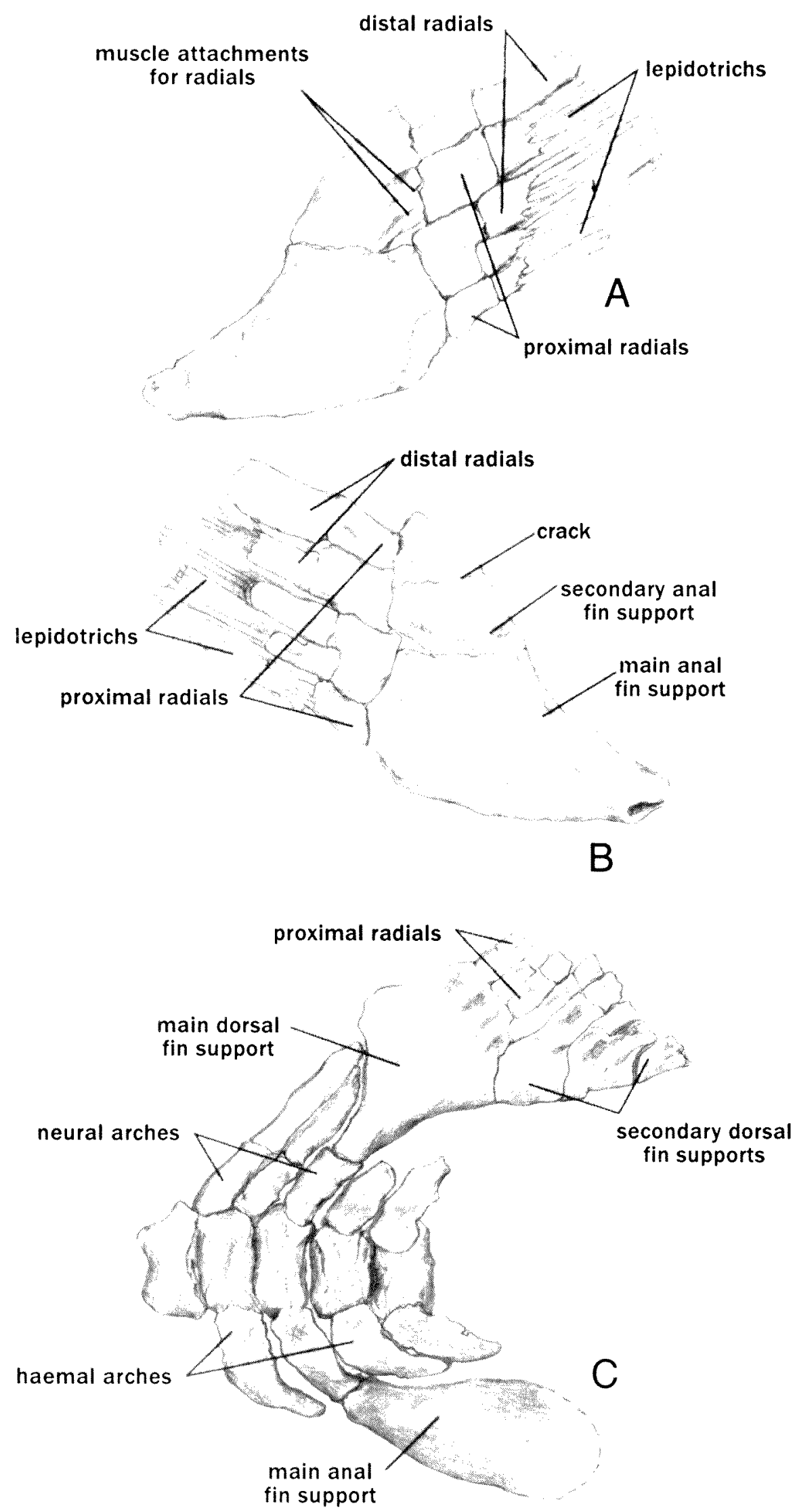

Figure 17 A, B. The two sides of the anal fin of WAM 86.9.645 drawn to show the support structures, the radials, and the lepidotrichs and their attachments. C. Reconstruction of ANU 49120 with the radials, neural arches and some of the haemal arches in position. 
radials are followed by one or two rows of distal radials. The most distal radials are deeply encompassed by the proximal lepidotrichs. The ventral edge of the main anal fin support has a flattened surface with slight lateral flanges that are extended into slight ridges. These ridges are parallel with the ridges on the main anal support plate. The most likely explanation of the structure is that it provided attachment for the muscles which activated the ventral lepidotrichs (see below).

Towards the anterior end of the main anal support plate on ANU 49116 lies a stellate array of ridges (Figures $1 \mathrm{~A}, \mathrm{~B} ; 18 \mathrm{C}$ ). These are similar to the ridges near the radial attachment. They are also present on the proximal radials. They probably mark the insertion points for muscles attached to the anal fin support and extending to the lepidotrichs. The stellate array has grooves running forward, and these probably mark the muscle fibres from the anal support to the axial skeleton, permitting the movement of the fin base. The proximal lepidotrichs are strong, long, slightly flattened proximally. Their outer faces have shallow grooves which probably mark the muscle attachment sites. ANU 49114 shows the inner face of part of the fin and these are well rounded. The radials are covered with lepidotrichs. This arrangement must have given the fin rays a great deal of support, and such an arrangement must be taken into account when considering the muscle attachment.

WAM 86.9.645 (Figures 16 D,E; $17 \mathrm{~A}, \mathrm{~B}$ ) is comparable in size to ANU 49116. It has the main support plate and a second posterodorsal plate of the same kind. On both specimens each radial support plate carries three articulations for radials. The main support plate has the upper two attachments fused together, while the lower one is separate. The small secondary plate has three attachments, the most dorsal one of which is much smaller than the others. The preserved radials are short in comparison with the proximal radials on ANU 49116, and one is a double structure with two plates joined together. It fits neatly against the double structure on the main support plate. The distal radials are long and extend back into the lepiditrichs as much as $1.3 \mathrm{~cm}$. Only the proximal lepidotrichs are preserved. In cross section and they vary in shape from ovate to flattened.

WAM 86.9.651 is the smallest specimen from which we have extensive postcranial material (Figure 16 F,G). The main support structure of the anal fin is $65 \%$ of that in ANU 49116 , and $48 \%$ of ANU 49114. The main support structure of the anal fin is all that is preserved of the structure, but the secondary support plate is attached to the main plate, and no sign of a bounding suture is present. The secondary plate is distinguished only because it extends more posteriorly. The main plate carries three radial attachments, but the smaller plate carries two rather than three radial attachments. Posteroventrally the main plate has the same distinguishing feature of a flared surface with slight lateral projections which is well shown on Figure 16 F. The lateral flanges do not extend uniformly along the whole length of the plate, but have a rounded extension on each side. On these there are small projections which have the appearance of ligament attachments. The position of the main support and the orientation of the projections suggest that the ligamenta would have been attached to the soft tissues, and would have been for stability rather than movement of the main support structure. The dorsal edge is like that of ANU 49116. The anterior attachment on the main plate is dorsoventrally bifacial, and very similar to that of ANU 49116. The dorsal face is the larger, and the ventral face is turned backwards at ca. $80^{\circ}$, indicating that the support would have a dorso-ventral movement.

\section{Second Dorsal Fin Structure}

Parts of this fin are preserved on ANU 49114, 49116, 49120, WAM 86.9.645 and 86.9.651. The fin supports are not complete on any specimen, but it is apparent that there is considerable variation in the arrangement of the secondary support structures.

We describe ANU 49116 first, as it is the most complete. The fin has a main support and five ancillary supports posterior to it (Figures $1 ; 18 \mathrm{~B}$ ). The main support is large, anterodorsally placed in the overall fin structure. The following five are much smaller and are arcuate in shape, each one fitting against the element in front. Each of these five elements has a finished blade-like ventral edge, without any sign of attachment.

The main support plate has a gently concave base which was continued by the bases of the subsequent arcuate plates. These bases are all rounded. The dorsal edge is more strongly concave and turns dorsally where it is broken off. The dorsal anterior end is lost, but presumably it was as is shown by the other specimens. The posterodorsal edge is very slightly concave in lateral view, and its surface is slightly flattened. The posteroventral edge is more concave and the ventral part of its edge is flattened where it is adjacent to the next plate. The posterior face has surfaces for the attachment of three radials. The posterior two thirds of the plate carry ridges which begin from an irregular ridge, and terminate against the radial attachment posteriorly. These are directly comparable with the ridges described for the anal fin above.

The first three arcuate secondary support plates are similar in shape. They can be oriented precisely in place because their edges are clear and because the ridges they carry can be aligned. The fourth plate is shorter, differently shaped because of the 

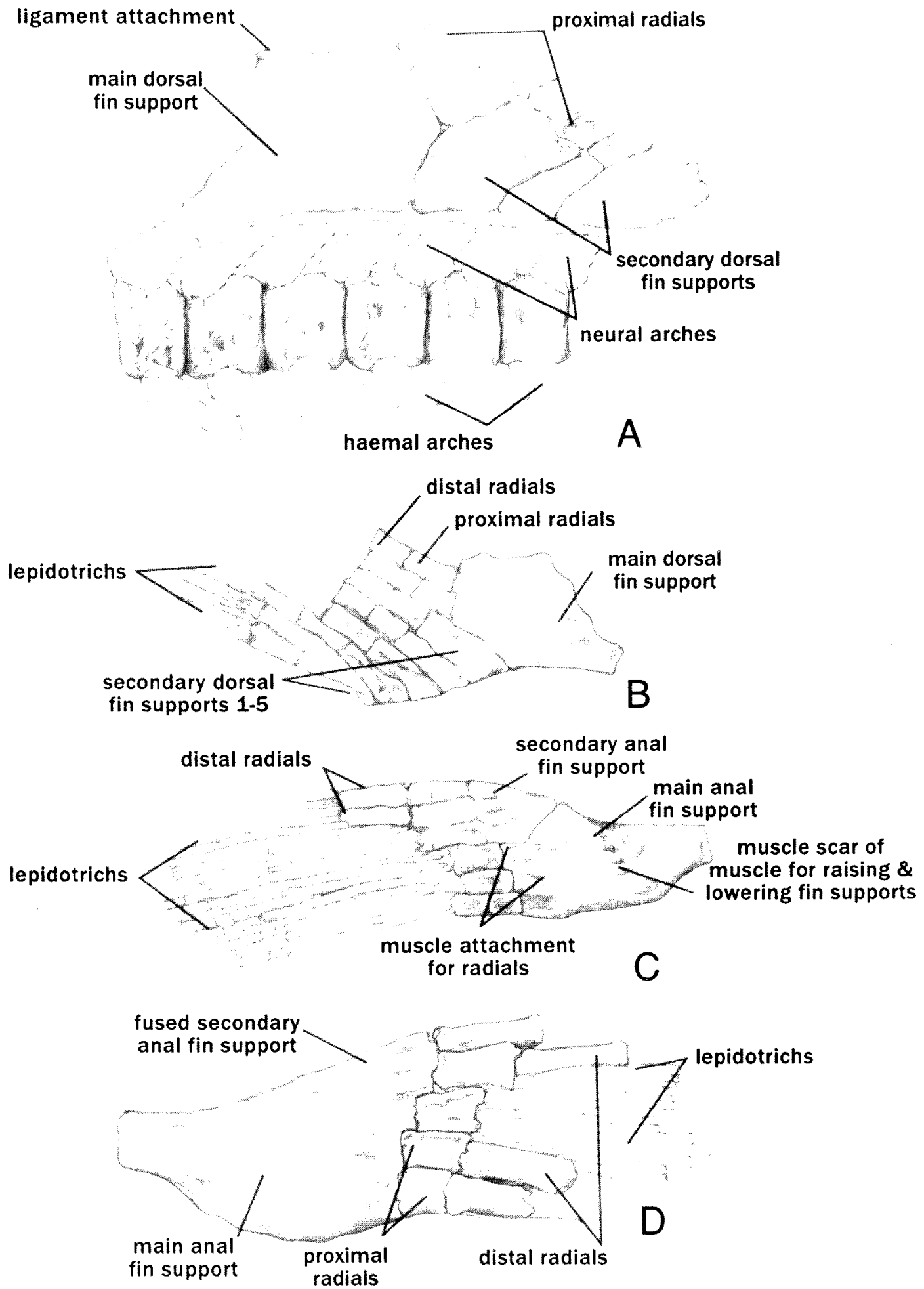

Figure 18 A. Reconstruction of WAM 86.9.645 showing the second dorsal fin and its relation to the inferred neural arches and haemal arches. Note especially the secondary support structures. B. The second dorsal fin from ANU 49116, showing the reconstructed organisation of the secondary support structures. C. The anal fin of ANU 49116, with its proximal and distal radials and some lepidotrichs. D. Anal fin of ANU 49114 with the proximal and distal radials restored to position.

increased inclination and its fitting into the third plate, and the fifth plate is even shorter and its shape is even more modified as it joins the fourth plate. Each of these plates has a single oblique ridge on its surface, and each has a radial attached at its end, except for the fifth one which has two radials, one of which is smaller than the others. This makes nine radials articulated to the support surfaces. As can be seen from Figures 1 and 18 B, the first radials are steeply inclined. 
Perhaps the most important part of these plates is that their ventral edges is blade-like and they show no sign of being attached to any other structure. They are internal to the fin. As ANU 49120 (Figures $16 \mathrm{H} ; 17 \mathrm{C}$ ) shows they are placed immediately above the the neural arches. They cannot be compared with the plates in such genera as Fleurantia and Scaumenacia in which the supports for the posterior of the fin rays are supraneurals. In fact, the structure in Griphognathus is similar to the Dipterus type with more supporting elements within the fin.

The proximal radials are long and narrow, being slightly dumbell-shaped in lateral view, and quadrate in cross section. They must have fitted closely together. The distal radials are not well preserved, but they are shorter and similar to the primary radials in other respects. The specimen does not have further radials aligned in any location, but some radials are attached in the lepidotrichs, and these must be third radials. They are similar in shape to the distal radials.

The lepidotrichs are not preserved in sequence. They are thinner than those on the anal fin, and are more rounded in cross section. There is a possibility that they may have occurred in clusters around each of the radials, but this is not clear.

On WAM 86.9.645, only the main fin support, three of the secondary fin supports, and a couple of broken radials are preserved. Nevertheless this is a most important specimen because almost the whole edge of the main support of the second dorsal fin is preserved (Figures $16 \mathrm{~A}, \mathrm{~B} ; 18 \mathrm{~A}$ ). The attachment surface is not quite complete, but it has left and right surfaces indicating that lateral movement was endorsed, as well as some dorsoventral movement (Figure $16 \mathrm{C}$ ). The anterior edge is strongly convex and it is sharply up-turned dorsally. The anterodorsal edge is truncated and where it joins the dorsal edge it has a small lateral projection on each side. This is comparable with the projections described on the main anal support structure described above. The dorsal edge also expands to these projections. All these edges are rounded and complete, and show no evidence of any other plate attached. The posterodorsal edge is slightly worn, but it has attachment surfaces for three proximal radials. These attachment surfaces are not completely isolated from one another because of wear. The posteroventral edge is almost straight and is attached to the next support structure.

On WAM 86.9.645, the first secondary support structure is large, slightly curved, and its anterior edge is close up against the posterior edge of the main support. It carries two oblique ridges along its length, and it supports two radials. The second support is long at its base and tapers dorsally where it supports one proximal radial. The third is also long at its base, but it expands dorsally to support three proximal radials, the posterior one of which has been partly broken off. This makes the number of radials to be nine. The posterior end of the third support was almost horizontal and there is no evidence that a fourth support lay behind it. With the secondary supports cleaned and their ventral edges aligned (Figure $18 \mathrm{~A}$ ) it is obvious that the radial attachments are strongly stepped backwards from dorsal to ventral.

ANU 49120 is a small specimen in which the second dorsal fin is attached to the same centrum as the anal fin (Figures $16 \mathrm{H} ; 17 \mathrm{C}$ ). In addition, the fin is not pushed down onto the axis, and a row of inclined neural arches lies between the fin and the axis. The main support has the standard structure of the species. Its attachment surface is small in comparison with the other specimens, and it has a laterally bifacial surface but no evidence of a dorsoventral bifacial surface. Posterodorsally it has attachment surfaces for four proximal radials, and each surface is marked off by low ridges on the lateral surface. The first of the secondary support structures is bulbous in outline, and constricts dorsally to allow the fourth proximal radial on the main support to fit into the pattern. It supports one radial. The secondary support has two oblique ridges, and it supports two proximal radials. The third support is much smaller, and fits neatly into the back of the previous support and carries two proximal radials. A neural arch lies close up against the ventral edge of the third support, thus indicating that no further supports were present. The number of proximal radials in the fin is nine. The ventral proximal radials have been stripped off, but the more dorsal radials are present. They are almost square in cross section. No lepidotrichs are preserved.

The main support structure on ANU 49114 is attached to two branches of the neural arches from successive centra (Figures 2; 19 A,B). The neural arches where the fin is attached are not uniform in this animal, and the more anterior arch is narrow and may have been broken away from the proximal part against the centrum. The neural arch behind the posterior attachment lies up against the main support plate. Part of one side of the main fin support is eroded away, but this support is nevertheless of considerable value, because the outline of the plate is still preserved. The main support is very similar to that described above for WAM 86.9.645. Judging from the size of the nearby proximal radials and the size of the attachment surface, the main support carried only two proximal radials. The first secondary support structure is arcuate, larger than the first support in any other specimen, and carries the articulation for two proximal radials. The second support structure is longer at the base than the first, and tapers to carry two proximal radials. The third is too incomplete to 

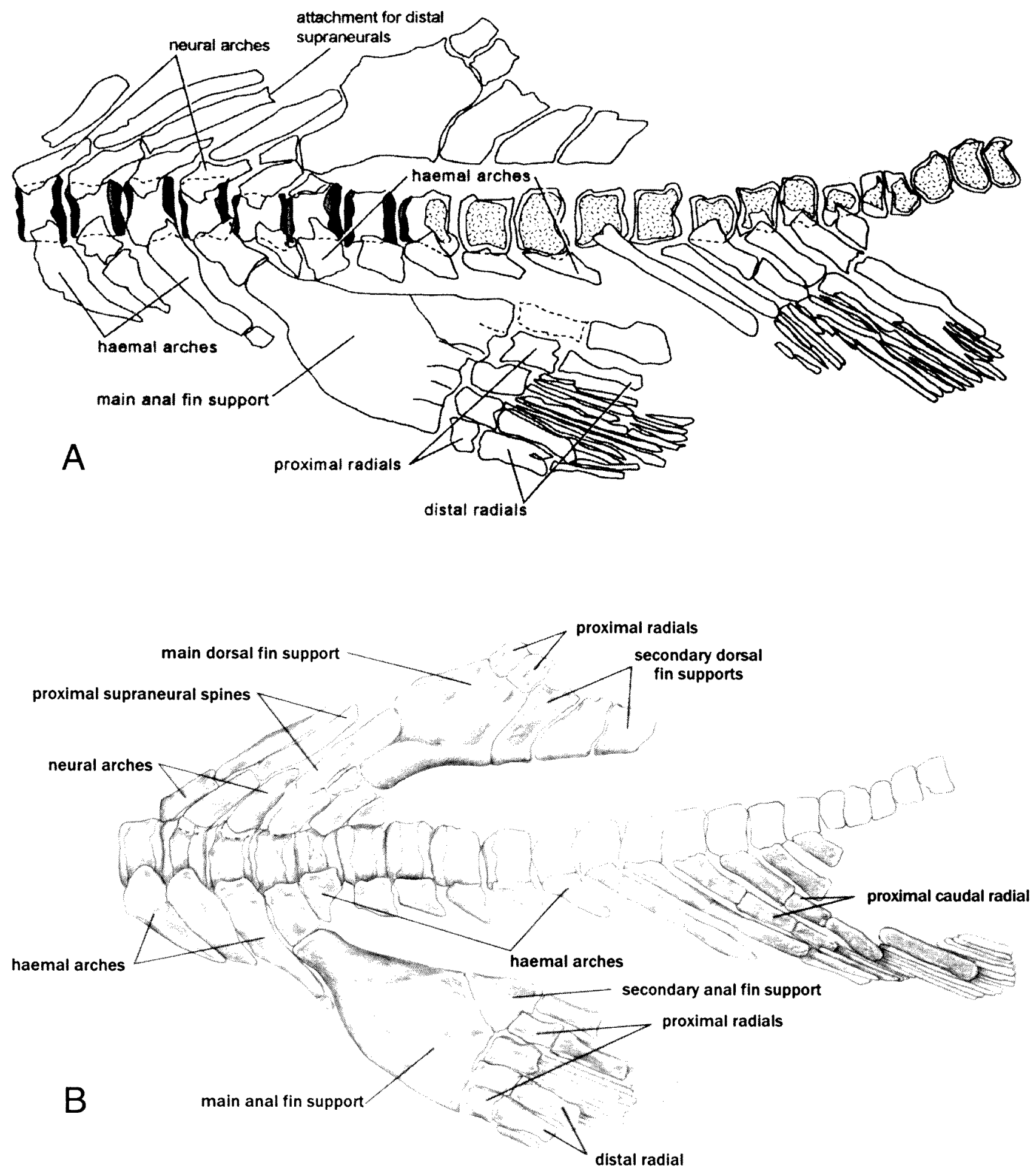

Figure 19 A. Skeleton of ANU 49114 restored to life position. Dotted lines indicate inferred positions of the bones which are not preserved. Dark stipple indicating the bone not covered by the perichondral layer, and originally covered by soft tissue surrounding the fluid between the adjoining faces of the vertebrae. B. Reconstruction based on Figure $19 \mathrm{~A}$.

be worthy of description, but it appears to have supported two proximal radials. No lepidotrichs are preserved.

Only a fragment of the main support plate of WAM 86.9.651 is preserved, but it shows all the features of this plate as preserved on WAM
86.9.645. The attachment surface is better preserved than on any other specimen, and it has two faces set left and right, approximately normal to each other. This is supported by WAM 86.9.645 and ANU 49120. Two secondary support structures are also present, though the sites of their attachment are not 
preserved. Each support has attachments for two proximal radials. The four proximal radials preserved are all thick walled, have rims around the attachment surfaces, and have flattened faces where they contacted adjacent radials.

\section{First Dorsal Fin Structure}

Only one example of the main support of the first dorsal fin is well preserved (WAM 86.9.645 C, Figure 7 D-F). On the same block are eleven centra, a number of broken neural arches, and fragments of haemal arches. The main fin support is isolated, and the neural arch to which it was attached is absent. This is not preserved on any of our other specimens. The presence of ten centra, with neural arches and neural spines attached posterior to the main support, indicates that there must have been a large distance between the first and second dorsal fins.

The support is robust, and lies in an unusual position (Figure $7 \mathrm{D}$ ). The surrounding structures are largely in correct orientation and we see no reason to consider that the support has been inverted. Note that the attachment end is protruded as in the second dorsal and anal fins, and there is little doubt that the orientation we have adopted is correct in this sense. The alternative is that this end was for the attachment to a radial, similar to that figured by Ahlberg and Trewin (1995, figure $9 \mathrm{~b}$ ) for Dipterus. We do not accept that possibility because the other end of the specimen does not have a surface that could be used for attachment, even though it has a small opening at its tip. This opening was at first thought to be a break in the wall, but the detail shows that it is real with a small indentation at one end. Possibly a small bone was attached at that point.

The attachment surface of the support is well preserved. It is dorsoventrally bifacial, indicating that it was capable of dorsoventral movements. Having fixed the dorsoventral orientation, it now remains to determine the anterior and posterior faces. Ahlberg and Trewin (1995, figures 5; 9) figure the lateral projection as dorsal in position, and this is supported by Long (pers comm.) who figures a specimen of Barwickia with the support in position. In the absence of other information, we follow this view. The ventral edge of the support unit is slightly concave, the anterodorsal edge is more strongly concave, is well rounded in cross section, and shows no sign of muscle or ligament attachment. This leaves the posterior edge as the only place for the attachment of the fin rays. This is unusual because this surface has no evidence of sharply bounded surfaces to which radials would have been attached like those on the other fins. Nor is there any evidence of radial ridges on the flanks of the support structures such as those on the other fin supports. As indicated above, the posteroventral edge of the posterior face was apparently open but

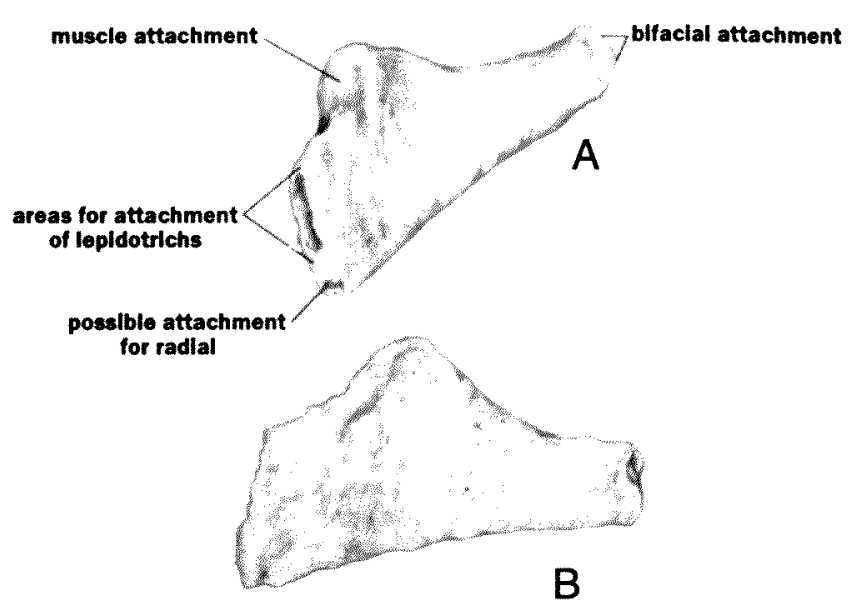

Figure 20 A. An oblique view of the support structure of the first dorsal fin from WAM 86.9.645. B. A lateral view of same.

it has no indication of surfaces to which radials could be attached. On the other hand it has slight radial ridges around the opening, suggesting muscle attachment. This may indicate that lepidotrichs were attached directly to the main fin support. Ahlberg and Trewin (1995, figure 9 b) show a similar arrangement in Dipterus, and the whole structure they described as "a single unjointed radial and an oblong basal plate." The lepidotrichs are shown in their figures $5 \mathrm{~b}$ and $9 \mathrm{~b}$ as having been derived from the anterior dorsal fin support and from the radial. In both Barwickia and Howidipterus, Long has observed proximal radials derived directly from the main fin support, and dividing into multiple lepidotrichs distally (Long pers comm.).

In G. whitei the posterodorsal part of the support is slightly expanded and has a posteriorly directed surface which has a median ridge dividing it ventrally. The significance of this surface is not understood.

\section{Caudal Fin Structure}

This fin is partly preserved on ANU 49114 and 49116, and an external mould with some fin skeleton and caudal scales still attached, is found on ANU 49285. The first radial of the caudal fin lies about nine centra posterior to the attachment of the anal fin. The specimen ANU 49114 is broken in this region. The final haemal arch before the caudal fin, is very long and it supports a short radial with a rounded end. The first caudal radial is longer, and extends down into the caudal lepidotrichs.

On ANU 49116 the haemal arches are also short and they have concave termini to which the caudal radials were attached, thus showing that the radials had lateral movement on the haemal arches. As would therefore be expected, the radials have proximal termini with a raised rim around the 

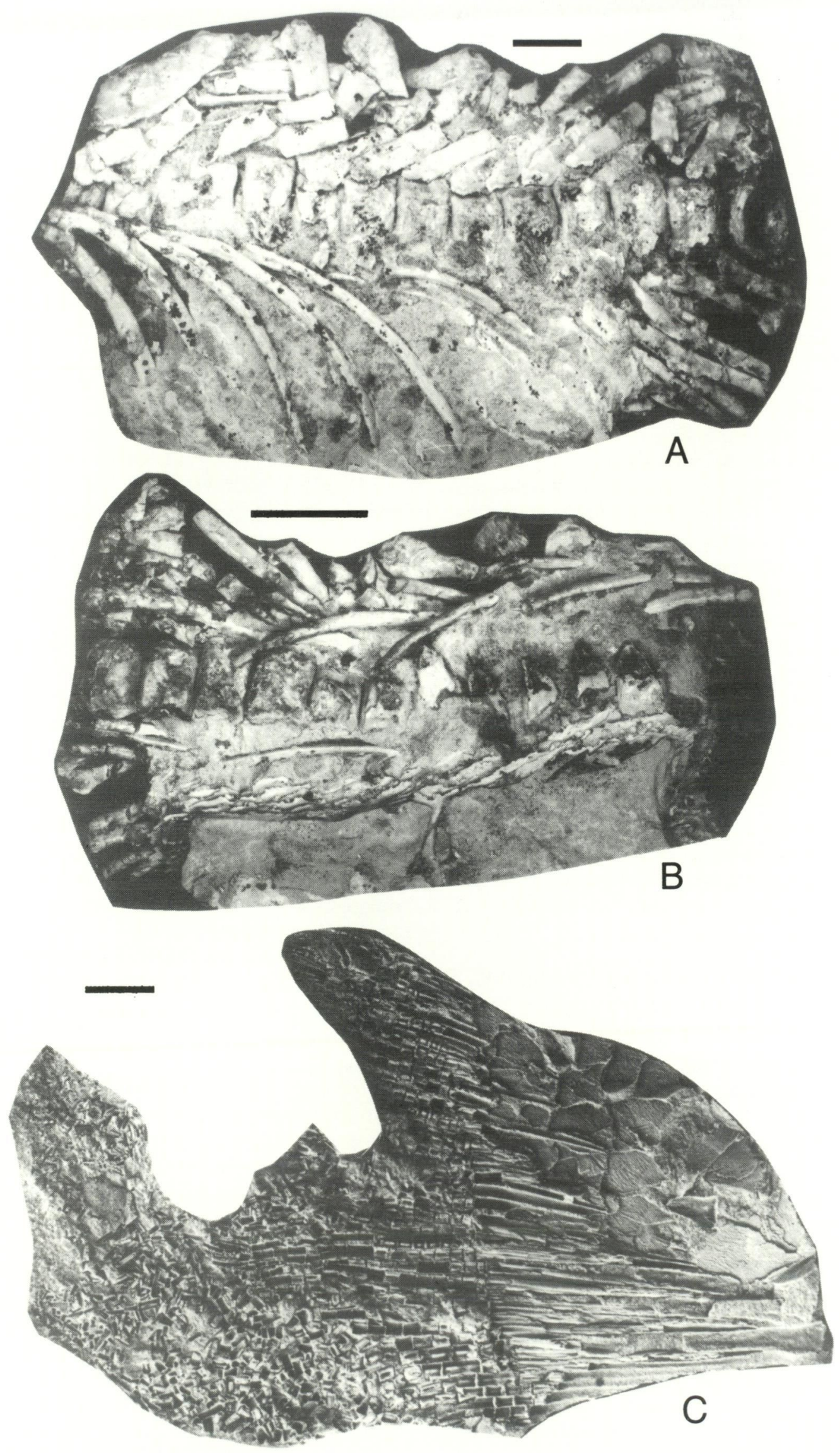

Figure 21 A, B. The two sides of WAM 86.9 .625 before final etching. The structures shown in Figure 4 L,M, were etched from this individual. C. Specimen as found in the field. ANU 49285. Note details on the surface of the scales, the fine structure of the lepidotrichs, and the anterior edge of the caudal fin. Scales $=5 \mathrm{~mm}$. 
terminus, and are slightly concave indicating that the ligament attachment to the haemal arches was strong and presumably very flexible. The radials are $2 \mathrm{~cm}$ long on the anterior part of the fin, but six radials back they shorten to about $1 \mathrm{~cm}$. All the radials are deeply embedded in the lepidotrichs, most of which are rounded in cross section, but others are flattened or have a quadrate section.

It is not known how many vertebrae are involved with the caudal fin as no tail is complete. However, there must have been at least 15 or 16 ossified centra present on ANU 49116, and judging from the shape of the caudal section, there could have been at least another 10 beyond these. Some of these may have been unossified.

A single specimen with the caudal fin attached to a few scales (ANU 49285, Figure $21 \mathrm{C}$ ) is identified as a specimen of Griphognathus because of its scale surface. It has long proximal lepidotrichs and ventrally it has an estimated 35 distal lepidotrichs. The first distal lepidotrichs were thick and with furrows along their inner surfaces. On the ventral part of the fin, they number up to twenty elements in each row. Some of the most distal lepidotrichs are also preserved. They are of comparable length to the more proximal ones, but they are only 0.3 $\mathrm{mm}$ in diameter. They also have a groove down their median faces. It is not possible to count their number, but on the ventral part of the fin it must have been about fifteen in a single row. The tips of the rays probably result from the splitting of the elements, and this can be observed on a limited scale. No lepidotrichs have cosmine on the surface.

The centra and haemal arches of the caudal region of WAM 86.9.651 have been described above.

\section{FUNCTIONAL SIGNIFICANCE OF MEDIAL FINS AND BODY}

In interpreting the postcranial structure of Griphognathus, it is necessary to examine first the head and the opercular region. The genus has a large head with all its bones ossified, its mandible tucked into its snout at full closure, and the whole profile indicating that it was a bottom feeder (Campbell and Barwick 1999, figures 2; 3). The opercular is large and has a tight fit against the pectoral lobe. The body scales are elongate, well ossified and strongly overlapping. As shown by Pridmore and Barwick (1993) the overlapping of scales is such that the lateral parts of the body are protected by 4-5 scale thicknesses. The ossification of the head in association with the heavy scalation and the shape and organisation of the scales, support the view that the animal was a bottom feeder.

\section{The Flexibility of the Body}

A number of factors enable us to comment on the flexibility of the body - the body shape, the shape of the head, the scale pattern, the design of the vertebral centra, the pleural ribs, and the pattern of the neural arches. We deal with these matters as follows.

(a) Pridmore and Barwick (1993) discussed the fineness ratios of the species and compared them with the values derived by Weihs and Webb (1983). The values for $G$. whitei are in excess of what is needed for cruising, sprinting or accelerating. The head is flattened and had the form of a bottom dwelling animal. The body tapers towards the posterior end, but the anal and second dorsal fins are close to the caudal fin.

(b) The scale pattern was explored by Pridmore and Barwick (1993), and we do not wish to alter their conclusions. On the flanks of the animal each scale was overlapped by six other cranial scales, and overlaps six more caudal scales. This would have restricted the lateral movement of the body. More caudally each scale appears to overlap only three scales, and to be overlapped by three others'. In other words the caudal region would have been less restricted.

(c) The centra as described above are amphicoelous throughout almost the whole body length. The edges of the centra show evidence of strong intervertebral soft tissues which would have controlled the stiffness of the body.

(d) The presence of neural arches which are attached to two centra would also have contributed to this stiffness. The edges of the centra are more or less in close contact (see Figure 12), though in life they would have been more separated. This suggests a restriction on the amount of lateral and vertical movement.

(e) The nature of the ribs supports the interpretation that the anterior part of the body was relatively inflexible. The ribs were large, closely spaced, postero-ventro-laterally directed, heavily ossified, and with their faces closely spaced. Markings on the rib surfaces indicate that they were well bound into the myosepta, and the presence of nodes along their distal and ventral edges suggests that longitudinal muscles were firmly attached. The orientation of the ribs shows that contraction of these muscles would not have caused much flexure of the body.

(f) The supraneurals and distal supraneurals are of value in determining mode of movement. On the anterior three segments the distal supraneurals are flat, and the crests of the distal supraneurals have ridges for the attachment of muscles. No doubt these distal supraneurals were situated close to the surface of the fish, and they lay in the myoseptum. Although they are prominent features, specimen AMF 72402 shows that the surface was only gently raised above the posterior surface of the head. The muscles attached to the distal supraneurals must 
have been attached to the connective tissue beneath the scale pockets or to the myotomes surrounding the supraneural arches. These would make the first few elements very stable as was suggested above by the structure of the centra. This stability is not matched by any other dipnoan, and the only sarcopterygian (Hitchcock, 1995) with large supraneurals is Eusthenopteron, which differs in many details. Their function in G. whitei has to be interpreted from first principles. Their stability would provide strength at the back of the head for the thrust generated posteriorly by the movement of the posterior fins, and this allowed the head to stir up the bottom sediment.

(g) The neurals and supraneurals extend for some distance along the body, and these would have been in a position to resist torsion when the animal moved.

Flexibility of the body was limited; the greatest flexibility was at the posterior, where the scales were thinner and the body narrower.

From their investigation of the postcranial material available to them, Pridmore and Barwick (1993) suggested that sub-carangiform or carangiform swimming was the norm for Griphognathus. With this view we are in agreement for the reasons given above. Other workers have analysed the movement of the Devonian lungfishes (Belles-Isles, 1992), and have concentrated on the position of the fins. In our view fin position is only one of the features, and it must be considered in the light of the other characters listed above. Taking all this into account, we now consider the medial fin structure.

\section{Role of the Medial Fins in Propulsion}

The caudal fin is long, and it was slightly upswept. The centra are well developed for a considerable distance back into the caudal region, and the haemal arches are well ossified. The caudal radials are long, well ossified and extend well into the lepidotrichs. The proximal lepidotrichs are thick, and some are ovate in section indicating a strong imbricate array. ANU 49285 shows that the proximal lepidotrichs become rapidly shorter dorsally, and the scales continue along the part of the caudal fin preserved. There is no evidence of scales preserved over the ventral proximal lepidotrichs, but the presence of large scales anterior to the lepidotrichs suggests that they were present. The capacity to move the fins increased towards the distal region of the fin. In comparison with Dipterus, this species has an elongate mobile part of the caudal fin.

The articulatory termini of the most anterior haemal arches where the caudal radials were attached, are markedly concave laterally, indicating the presence of a large mobile attachment to the radials, and considerable lateral movement of the radials. The attachment surface of the radials is swollen, and the surface is surrounded by a thickening. This pattern also indicates a strong junction with the haemal arches. More posteriorly, the ends of the haemal arches are flattened and join with the flattened ends of the radials. This design supports the argument that the tail was strong, that movement of the ventral part of the fin took place by lateral movement at the haemal junction, but slighter movement took place more dorsally. Strength was added to the movement by the elongate radials which extended so far into the long proximal lepidotrichs, and strong muscles which leave grooves on both the haemal arches and the radials. Movement of the caudal region must have been interrelated with the action of the distal lepidotrichs.

We have been unsuccessful in finding other sarcopterygians with which to make comparisons of the anal fin. Coelacanths, as represented by Latimeria, have a support system which has almost no features in common with Griphognathus, and its axis has a single row of ossifications arranged in a unique way. Eusthenopteron has some features in common with three radials, but it has only a small main support, only one set of radials and short proximal lepidotrichs. It was a pointed fin situated well in front of the caudal arch.

Judging from the shape of the haemal arches which are bent back at a low angle to the axial column in this region, the anal fin in Griphognathus lay close up under the body. The fin supports are variable in shape and number, sometimes having only one unit and more commonly two. The attachment edge of the main support is dorsoventrally bifacial, with the lower face being set approximately normal to the upper. Obviously this allowed the support to move dorsoventrally with respect to the animal body. To activate this system, muscles must have run from the support unit to the haemal arches. Such muscle scars are present on the anterior part of the main support. Scars are also present running posteriorly to the surfaces where the radials were attached. These must have been powerful muscles judging from the deep grooves they leave in the surface of the support unit. This dorsoventral movement raises an interesting point, because the articulation gives no indication that the lateral movement of the supports was part of the design. This is understandable because the main fin support is large and lies between five pairs of myotomes which must have provided lateral restraint. In addition, the radials are heavily ossified, each joined by a flat surface to the main support along a staggered line of junction which did not provide a unified hinge for movement, and joined to the main support by strong muscles which ran along their lengths. The proximal radials were quadrate in cross section, and 
had a strong face-to-face junction with similarly shaped ends on the main support, indicating a minimum amount of movement along this junction. These are followed distally by a line of distal radials with quadrate cross sections, and with strong faceto-face junction with the proximal radials. These distal radials extended from 1.0 to $1.5 \mathrm{~cm}$ into the proximal lepidotrichs, which are thick structures and are closely bound together. All this means that most of the anal fin was a relatively rigid structure, and the main movement of the fin was caused by movement of the distal lepidotrichs, of which we have little evidence. Such a view is supported by the presence of a flattened surface at the posteroventral end of the main support, and the presence of lateral expansions on these flanges being for the attachment of ligaments. These would have been attached to the myotomes, and would have stabilised the ventral end of the main support.

What would be the function of such a large anal fin? Firstly, since it had some dorsoventral movement, and when it was ventrally directed it would lift the caudal region, an important point for a bottom dwelling animal. This point is supported by the shape of the head. Secondly it would have acted with the caudal fin to produce a lepidotrichial sweep also causing the tail to rise and forcing down the head, but we have no indication of the presence of distal lepidotrichs in our specimens. If they were present they could also have acted with those of the second dorsal fin conceivably to provide some balistiform propulsion, but this is a suggestion which awaits the discovery of the distal lepidotrichs. Consequently we see the anal fin as providing little in the way of propulsive force for forward movement, but providing an uplift for the posterior of the animal and providing propulsion to push the head downwards during feeding from the sediment.

The second dorsal fin is another complex structure, as it is in most Devonian dipnoans. It has a main and several ancillary support units, the main one being several times as large as the others. The attachment surface of the main support unit is laterally bifacial, with its two facets so arranged that lateral movement was possible with respect to the neural arches to which it was attached. The auxillary supports, the ventral edges of which have no signs of attachment to the underlying neural arches, and hence they were able to move laterally independently of the main support. This is supported by the fact that they all fit together along closely placed margins, and they must have been able to move one against the other. The whole support structure of the fin is massive, and its proximal part must have been largely enclosed within myotomes. Distally it carries eight to nine proximal radials, and these are followed by a set of distal radials. The support units have elongate ridges and grooves which continue onto the radials, indicating that the muscles joining them were strong. Each distal radial has up to ten lepidotrichs attached to it.

The attachment of the proximal radials to the support structures does not form a straight line, but consists of a series of offsets, the more ventral ones being more posteriorly placed. Hence it does not make a linear hinge, and the radials may have been able to move independently of one another.

A most interesting point is the small anterodorsal scar on the main support which has a small lateral process on each side. Note that this is placed at the anterior end of the support rather than at the posterior as in the anal support, and that it is much smaller. Assuming that small connections with the myotomes were attached to these points, these would not have had a stabilising effect on the support, but would have given the structure an axis along with the main support, around which lateral movement would have taken place.

The first dorsal fin is poorly understood. The attachment scar is bifacial dorsoventrally, again indicating dorsal and ventral movement rather than lateral. Assuming that we have interpreted the fragments we have correctly, this fin would have had short lepidotrichs and presumably they would have an undulatory movement. They would have been so small that they would not have been able to propel the animal, and presumably they would have been to provide stability, a feature mentioned by Alexander (1970).

\section{Summary of Locomotion}

We conclude that the body shape does not indicate fast movement, but that it had the capacity to lift the tail and push the head down into the substrate. The strength of the caudal region shows that it acted as a gross propellant by movement of the whole region in an undulose fashion. The caudal fin would have been oar-like with the junction between the haemal arches and the radials flexible, proximal lepidotrichs embedded in robust scales, and the distal fins being small with respect to the whole animal.

This would be supported by the anal fin which was rather a rigid structure and a with a capacity to sit ventrally on the substrate. Its long lepidotrichs indicate that movement would have been possible mainly through the distal lepidotrichs, and their position close up under the caudal fin, shows that it would act with the caudal fin to lift the tail. The posterior position of the second dorsal fin, its position close to the body of the fish, and the number of secondary support structures, indicates that it would have acted to propel the fish forwards if fully active and would have counterbalanced the strong action of the caudal and anal fins where necessary. 


\section{COMPARISON WITH OTHER DEVONIAN DIPNOANS}

\section{Centra}

The specimens of Jarvikia and Soederberghia worked on by Schultze (1970), are not complete, and we have not been able to make useful comparisons with them. The structure of the centra in $G$. sculpta and $G$. minutidens provide the only information against which the centra of $G$. whitei can be directly compared. These also have been described by Schultze (1970). The specimens he described and figured on Pls 39 and 40 , have centra about $5 \mathrm{~mm}$ and $7 \mathrm{~mm}$ across, and in our terms it is about the same size as our smaller individuals. Our comparative comments have to be restricted to these juvenile stages of growth.

The central core around the notochordal canal is made of the same material in the two species, and the marginal tissue as shown in Schultze (pl. 39, fig. $1 b)$ is also comparable. Comparisons with the lamellae are difficult to make, as we have not seen the Liesegang Rings in our species. The large open spaces in the lamellar region are also missing, and G. sculpta does not have long narrow pores in the lamellae.

One important point is that the centra and the ribs of Griphognathus whitei are strongly ossified, as also are the neural and haemal arches. Scaumenacia and Fleurantia both have ossified neural and posterior haemal arches, but their centra are not ossified. In both these genera the ribs extend back to the anterior end of the second dorsal fins, but in Griphognathus there are at least 12 centra anterior to the second dorsal fin before the most posterior ribs appear.

\section{Fin Structure}

The postcranial skeleton of Dipterus valenciennesi from the Middle Devonian, and Rhinodipterus ulrichi, Scaumenacia curta, and Fleurantia denticulata and Griphognathus sculpta and G. multidens from the Late Devonian, have been described, and provide a good basis for an understanding of the Devonian postcranial skeletons. Of these, the material of Rhinodipterus ulrichi is the least organised and shows fewer elements of the skeleton than the others. In addition the genera Barwickia Long and Howidipterus Long from the Givetian of Victoria have given us more information on Late Devonian changes, but the detailed description is still in preparation. Data on these genera have been made available to us by Dr John Long of the Western Australian Museum.

First we make a comparison with G. sculpta which comes from the Frasnian at Bergish-Gladbach, Germany. The median and anal fins are known from distal skeletal units outside the scales, and so no comparison with the fin support structures can be made. The ossified centra are present in the posterior part of the skeleton, but they contain no ossified haemal or neural arches. The lepidotrichs are very similar to those on G. whitei.

G. whitei is closer to Dipterus in many respects than it is to any other Devonian dipnoan, especially in the supporting plates that underlie the first and second dorsal fins and the anal fin. Scaumenacia and Fleurantia have a simple anal fin support. Fleurantia has a small support for the first dorsal fin, but this also is a simple structure different from that in $G$. whitei. Both these latter fish also have a second dorsal fin composed of numerous radials each given off from supraneural arches. These features are an advance on the more primitive Dipterus stage in which the second dorsal fin is short, and is not closely associated with the caudal fins, which is a feature of Carboniferous and later genera.

$G$. whitei has a main support plate and a variable number of smaller plates carrying proximal and distal radials. This does not mean that it is a morphological intermediate between the Dipterus level and the Fleurantia level for the following reasons.

It has been commonly accepted that the support structures for the median fins arose from the junction of a number of parallel radials (Jarvik 1980). Ahlberg and Trewin (1995: 171) comment that in the typical sarcopterygian "posterior dorsal or anal fins support, comprising a basal plate and a number of parallel radials, is derived from a row of independent radials without a basal plate". Comparatively they indicate that a row of independent radials "seems to be the primitive gnathostome condition", and that the basal plate was formed from "fused basal segments of originally separate radials". This statement which adheres to the view of metamerically sequential units each giving rise to the radials, does not take into consideration the possibility that at the origin of the sarcopterygians there may have been a sudden major change in the genetic control of fin supports. After all, we see no record of any forms earlier or later stratigraphically, which show evidence of grouping of radials to make larger fin supports. Miles (in Moy-Thomas and Miles 1971: 111) commented that "the first appearance of the crossopterygians in the Lower Devonian is in a disconcertingly fully developed condition, and in structure they are quite distinct from actinopterygians". In the thirty years since then we see no reason to change this statement, except that the sarcopterygian genus Psarolepis may have come from the Late Silurian.

In our view the fossil evidence supports the concept that the preserved sarcopterygian primitive condition consisted of a support unit, probably without secondary support structures. Even in genera with short second dorsal fins such as 
Dipterus and G. whitei there is evidence that two or three distal fin radials may derive from a single proximal fin radial, and this phenomenon can be seen in the anal and the caudal fins of Chirodipterus as shown in our collections from Gogo. The fin structure of these forms indicates that the single fin support gives rise to multiple divisions to produce the complex structure of the fins.

As has been well known for many years (Dollo 1895, Westoll 1949) the shape of the medial anal and dorsal fins together with caudal fins, have produced a diphycercal organisation (Long 1993, figure 7; Ahlberg and Trewin 1995, figure 11). It is difficult to produce this long series of forms from a primitive such as Dipterus, within which the fin radials were supported from a single support plate attached to a single neural arch. Most of this change took place in the Devonian, and the only evidence of change in the fin supports is towards the reduction of the main supports and the introduction of new ancillary supports. This is well illustrated by the genera Barwickia Long and Howidipterus Long, in which a main support lies at the anterior end of the second dorsal fin, and an extended posterior part of the fin made up of several radials each attached to a single neural arch.

In G. whitei up to five secondary supports are found behind the main fin support in the second dorsal fin, the number varying from individual to individual. The ventral edge of these secondary supports is a sharp-edged linear strip without any signs of an attachment edge. These supports are totally confined to the fin, and they lie at an angle to the neural arches beneath them. In other words they have an entirely different origin from the radials found in the graded sequence of genera such as Scaumenacia and Fleurantia. In G. whitei the second dorsal fin does not approach the caudal region to make contact with an epichordal lobe. It seems most likely that both second dorsal and anal fins in G. whitei were developed to produce structures permitting head down feeding, whereas the development of the elongate fins which join with the epichordal fin were used for free swimming.

\section{Neural Arches and Dorsal Elements}

Few Devonian dipnoans preserve skeletons of the neural regions. A summary of the data was given by Schultze (1975), and some specimens were figured by Lehman (1959). More recently described species (Long, in prep) in which the axial region is preserved, do not show any unusual features. Once again, the best comparison is with $D$. valenciennesi. Ahlberg and Trewin (1995, figure 9b) published a reconstruction from a badly dismembered specimen, but the supraneurals are long and thin and highly inclined. They have no similarity to those of $G$. whitei. As we have indicated in the section on function, the peculiar arrangement in $G$. whitei is a specialisation related to its mode of feeding.

\section{Cranial Ribs}

Cranial ribs occur in living lungfishes where they are associated with air breathing. They are attached to the back of the cranium rather than to the vertebral column, they are wide paddle-shaped structures, and they hang down posterior to the cranium. The presence of cranial ribs does not prove the presence of air breathing, because so many other factors are involved in producing the passage of air. Long (1993) discovered the presence of these ribs in two genera from the fresh water beds in the Givetian at Mt Howitt, in Victoria, and they are associated with other features of air breathing animals. We have attempted to find such structures in G. whitei, though air breathing would not be expected in a bottom dwelling marine animal of this kind. To date we can find no evidence of where they would have attached to the cranium, and though we have ribs attached to the first few vertebrae, we can find no evidence of cranial ribs in our etches and this correlates with the inflexibility of the neck which was described above.

\section{ACKNOWLEDEMENTS}

Thin sections have been prepared by John Vickers of the Geology Department, A.N.U. Specimens of Griphogathus were collected on two trips by us to the Gogo locality, by Gavin Young of the Australian Geological Survey Organisation (now of the Geology Department, A.N.U.), and by John Long of the Western Australian Museum. John Long also provided us with a preprint of his paper on Barwickia and Howidipterus. Our field work and laboratory work was done with the assistance of an A.R.C. grant. Work in the A.N.U. was done with the permission and support of the Head of the Geology Department.

\section{REFERENCES}

Ahlberg, E. and Trewin, N.H. (1995). The postcranial skeleton of the Middle Devonian lungfish Dipterus valenciennesi. Transactions of the Royal Society of Edinburgh 85: 159-175.

Belles-Isles, M. (1992). The modes of swimming of sarcopterygians. In Mark-Kurik, E. (ed) Fossil fishes as living animals: 117-130, Academy of Sciences of Estonia. Academia 1.

Campbell, K.S.W. and Barwick, R.E. (1988). Uranolophus: a reappraisal of a primitive lungfish. Memoirs of the Association of Australasian Palaeontologists 7: 87-144.

Campbell, K.S.W. and Barwick, R.E. (1998). A new toothplated dipnoan from the Upper Devonian Gogo 
Formation and its relationships. Memoirs of the Queensland Museum 42: 403-437.

Campbell, K.S.W. and Barwick, R.E. (1999). Dipnoan fishes from the Late Devonian Gogo Formation of Western Australia. Records of the Western Australian Museum Supplement 57: 107-138.

Cloutier, R. (1996). Dipnoi (Akinetica: Sarcopterygii) In Schultze, H-P. and Cloutier, R. (eds), Devonian Fishes and Plants of Miguasha, Quebec, Canada: 198-226, Friedrich Pfeil, München.

Dollo, L. (1895). Sur la phylogénie des Dipneustes. Bulletin Sociéte belgique Geologie et Paléontologie et Hydrologie 9: 79-121.

Hitchcock, E.C. (1995). A functional interpretation of the anteriormost vertebrae and skull of Eusthenopteron. Bulletin de la Muséum National d'Histoire Naturelle, Paris, Série 17, Section C 1-4: 248-285.

Graham-Smith, W. and Westoll, T.S. (1937). On a new long-headed dipnoan fish from the Upper Devonian of Scaumenac Bay, P.Q., Canada. Transactions of the Royal Society of Edinburgh 59: 241-256.

Jarvik, E. (1959). Dermal fin-rays and Holmgren's principle of delamination. Kunglinga Svenska Vetenskapsakademiens Handlingar (4) 6: 1-51.

Jarvik, E. (1980). Basic structure and evolution of vertebrates. Vol. 1. Academic Press, London.

Lehman, J-P. (1959). Les Dipneustes du Dévonien supérieur du Groenland. Meddelelser om Grøenland 160: $1-58$.

Long, J.A. (1993). Cranial ribs in Devonian lungfishes and the origin of dipnoan air-breathing. Memoirs of the Association of Australasian Palaeontologists 15: 199209.
Miles, R.S. (1977) Dipnoan (lungfish) skulls and the relationships of the group: a study based on new species from the Devonian of Australia. Zoological Journal of the Linnean Society of London 61: 1-328.

Moy-Thomas, J.A. and Miles R.S. (1971). Palaeozoic Fishes. Chapman and Hall, London.

Pridmore, P.A. and Barwick, R.E. (1993). Post-cranial morphologies of the Late Devonian Dipnoans Griphognathus and Chirodipterus and locomotor implications. Memoirs of the Association of Australasian Palaeontologists 15: 161-182.

Schultze, H-P. (1970). Der Histologie der Wirbelkörper der Dipnoer. Neues Jahrbuch fur Geologische und Paläontologische, Abhandlungen 135: 311-336.

Schultze, H-P. (1975). Das Axialskellett der Dipnoer aus dem Oberdevon von Bergisch-Gladbach (Westdeutschland). Colloques International Centre Nationale Researche Scientifique 218: 149-159.

Weihs, D. and Webb, P.W. (1983) Optimisation of locomotion. In Webb, P.W. and Weihs, D. (eds), Fish biomechanics. Praeger, New York.

Westoll, T.S. (1949). On the evolution of the Dipnoi. In Jepsen, G.L., Simpson, G.G. and Mayr, E. (eds), Genetics, Paleontology and Evolution: 21-184. Princeton University Press, Princeton.

Young, G.C., Barwick, R.E. and Campbell, K.S.W. (1989). Pelvic gridles of lungfishes (Dipnoi). In Le Maitre, R.W. (ed) Pathways in Geology, Essays in honour of Edwin Sherbon Hills: 59-75, Blackwell, Melbourne.

Manuscript received 28 May 2001; accepted 22 November 2001. 